\title{
Classification and literature review of integrated lot-sizing and cutting stock problems
}

\author{
Gislaine Mara Melega ${ }^{a}$, Silvio Alexandre de Araujo ${ }^{\mathrm{a}, *}$, Raf Jans ${ }^{\mathrm{b}}$ \\ a Departamento de Matemática Aplicada, IBILCE, UNESP - Universidade Estadual Paulista, São José do Rio Preto 15054-000, SP, Brasil \\ ${ }^{\mathrm{b}}$ HEC Montréal and CIRRELT, H3T 2A7 QC, Canada
}

\section{A R T I C L E I N F O}

\section{Article history:}

Received 31 January 2017

Accepted 2 January 2018

Available online 10 January 2018

\section{Keywords:}

Cutting stock problems

Lot-sizing problems

Integrated problems

Review and classification

\begin{abstract}
A B S T R A C T
The aim of this paper is to classify the literature related to the integration between the lot-sizing and cutting stock problem. A deterministic mathematical model, that considers multiple dimensions of integration and comprises several aspects found in practice, is proposed. This model is used as a framework to classify the current literature in this field. The main classification of the literature is organized around two types of integration. In a planning horizon which consists of multiple periods, the inventory provides a link between the periods. This integration across time periods constitutes the first type of integration. The proposed model also considers the production of different types of items at three different levels: objects are fabricated or purchased and next cut into pieces which are then assembled into final products. The integration between these three production levels constitutes the second type of integration. The classification indicates that, even though many papers in the current literature analyze an integrated lot-sizing and cutting stock problem, they vary widely with respect to the level of integration on the time and production level dimensions. Furthermore, our analysis indicates that the current models also consider varying assumptions with respect to the inventory, the production capacities and the setups. Finally, we point out some possible interesting areas for future research.
\end{abstract}

(c) 2018 Elsevier B.V. All rights reserved.

\section{Introduction}

The lot-sizing problem and the cutting stock problem have been the object of extensive research for more than 50 years. Much progress has been made with respect to formulations and solution methods for these two problems. Most of the research has been focused on solving these problems separately, since each problem in itself can be difficult to solve. However, with the fast progress in optimization theory, software, hardware and, a better understanding of the individual problems, as well as the dependencies among decisions observed in practical cases, more attention has been paid to the integration of these two problems in recent years. This integration is the subject of interest in this paper and it is referred to in the literature as the integrated (combined) lot-sizing and cutting stock problem. The interest in this problem often originates from direct practical applications of the integrated environments in various industries. For example, in the paper industry, large reels are manufactured or purchased and a decision about the size of the lots must be taken. Next, the large reels are cut into smaller reels

\footnotetext{
* Corresponding author.

E-mail addresses: gislainemelega@gmail.com (G.M. Melega), saraujo@ibilce.unesp.br (S.A.de Araujo),raf.jans@hec.ca (R. Jans).
}

that might correspond to customer requests, and a decision related to the cutting stock problem is needed. Part of the smaller reels can be cut again into paper sheets, according to some decision related to the lot size for the papers sheets. In the furniture industry, wooden plates are produced or purchased from different suppliers, and a decision about the size of the lots to be produced or purchased from each supplier must be taken. Then, these wooden plates are cut into several wooden parts (in a two-dimensional cutting stock process) to be assembled into the final products. A decision about the size of the lots of final products is also needed, and consequently there are three levels of decisions. Other examples can be found in the fiberglass industry, where fiberglass plates are cut to manufacture printed circuit boards and in the aluminium industry, where aluminium profiles are cut to make several window types. The basic idea of the integrated lot-sizing and cutting stock problem is to consider, simultaneously, the decisions related to both problems so as to capture the interdependency between these decisions in order to obtain a better global solution. Several papers from the literature present computational results showing the benefits of considering an integrated approach instead of taking decisions separately (Gramani \& França, 2006; Gramani, França, \& Arenales, 2009; and Vanzela, Melega, Rangel, \& de Araujo, 2017). 
The Lot-Sizing Problem (LSP) considers the tradeoff between the setup and inventory holding costs to determine the minimal cost of a production plan for one (or several) machine(s) in order to meet the demand for each item. The LSP can be classified according to several characteristics, such as, the number of levels in the production structure (single level or multi-level), demand (constant or dynamic), time horizon (finite or infinite), time periods (continuous or discrete) and the consideration of capacity constraints and setup times. In the literature, many papers address the lot-zing problem in different environments, and we highlight the review papers of Drexl and Kimms (1997) Karimi, Ghomi, and Wilson (2003), Brahimi, Dauzere-Peres, Najid, and Nordli (2006), Buschkühl, Sahling, Helber, and Tempelmeier (2010), Jans and Degraeve (2008), Robinson, Narayanan, and Sahin (2009), Glock, Grosse, and Ries (2014) and Copil, Wörbelauer, Meyr, and Tempelmeier (2017). A thorough discussion of lot-sizing problems is provided in the book by Pochet and Wolsey (2006) and a review of solution approaches can be found in Jans and Degraeve (2007).

The cutting stock problem (CSP) involves the cutting of large objects available in stock into smaller pieces, in order to meet the demand of the pieces and optimize an objective function, such as the minimization of the total waste, the minimization of the costs of the objects used, or the maximization of profit. The economic and operational importance of the cutting stock problem and the difficulties in solving it, have motivated the academic community in this area to develop efficient solution methods, as can be seen in the review papers and special editions of Hinxman (1980), Dyckhoff, Kruse, Abel, and Gal (1985), Dyckhoff, Scheithauer, and Terno (1997), Arenales, Morabito, and Yanasse (1999), Hifi (2002), Wang and Wäscher (2002), Oliveira and Wäscher (2007), Morabito, Arenales, and Yanasse (2009) and Gomes, Gonçalves, AlvarezValdés, and de Carvalho (2016). In order to synthesize and classify the literature, Dyckhoff (1990) introduced a typology for cutting and packing problems (with includes the cutting stock problem), and Wäscher, Haußner, and Schumann (2007) presented changes in Dyckhoff's typology, refining aspects of the problems analyzed. The typology is based on four characteristics of the problem, which are dimensionality (i.e. the number of relevant dimensions in the cutting process), type of assignment (i.e. the selection of objects and pieces), assortment of large objects (i.e. the types of objects) and assortment of small pieces (i.e. the types of pieces).

The literature mostly deals with the lot-sizing problem and cutting stock problem separately through models that capture just the main trade-off in each problem. However, some review papers (Drexl \& Kimms, 1997; Jans \& Degraeve, 2008; Thomas \& Griffin, 1996) have pointed out a tendency that dealing with various problems in an integrated way is an important aspect of future research. Over the last years, this tendency was observed for the lot-sizing and cutting stock problems, and the analysis of practical cases focusing more on the incorporation of relevant industrial concerns provided a further impetus. When various authors refer to an integrated lot-sizing and cutting stock problem, they often consider different assumptions with respect to the level of integration considered, and hence present quite different models. We propose a generalized formulation for the integrated problem, in a deterministic environment, which considers two main aspects of integration, i.e., the integration across time periods and the integration between production levels. This model provides an instrument that allows us to clearly classify the various models proposed in the literature. The classification is performed by first presenting a formulation of a generalized 3-level integrated model composed of three production levels and multiple time periods, with the purpose of capturing the greatest degree of integration between the lot-sizing and the cutting stock problem. The models in the literature are next classified according to their characteristics with respect to the time horizon and production levels. Models that

consider the integration among time periods (i.e. where inventory provides a link between the periods), as well as, integration between production levels (i.e. with decision variables associated with more than one level) are classified as integrated lot-sizing and cutting stock models. Models that consider the integration between production levels, but not among time periods, are classified as single-period multi-level production and cutting stock problems. Models that consider the integration among time periods, but not between production levels, are classified as multi-period cutting stock problem. Other important issues related to the objects, pieces and final products, as well as the consideration of capacity constraints and setups at different levels are also evaluated.

The presentation of a generalized 3-level integrated model and the classification of the various integrated models in the current literature are the main contributions of this paper. To the best of our knowledge, no general review and analysis of integrated lot-sizing and cutting stock problems have been done so far. Furthermore, this analysis also allows us to point out interesting areas for future research. The scope of the paper is limited to the modeling aspects related to the integrated models. A detailed discussion of the solution approaches is hence left out.

This paper is organized as follows. In Section 2, some basic models for the lot-sizing problem and cutting stock problem are presented and discussed. In this section, the generalized 3-level integrated lot-sizing and cutting stock problem proposed in this paper is also described. This model considers that all the parameters are deterministic. Section 3 presents the classification criteria used and the classification and discussion of the studies on integrated problems. Finally, Section 4 presents the conclusions of the paper and discusses directions for future research.

\section{Mathematical models}

In this section, basic models for the lot-sizing problem and cutting stock problem are presented, as well as a brief discussion of some relevant extensions for each problem. Next, the generalized 3-level integrated model is proposed.

\subsection{Discussion of the lot-sizing problem}

The lot-sizing problem was first introduced by Wagner and Whitin (1958) for a single item and by Manne (1958) for multiple items and with capacity constraints. In this section, we consider a capacitated lot-sizing problem with setup times, which was proposed by Trigeiro, Thomas, and McClain (1989) and further analyzed in Degraeve and Jans (2007), among others. The demand is dynamic over time and there is a single resource with limited capacity. Several products can be produced within the same period of time which makes this a big-bucket model. Setup costs and setup times are considered. This problem is commonly referred to in the literature as the CLSP problem, i.e., capacitated lot-sizing problem. Consider the following sets, parameters and decision variables:

Sets:

$T: \quad$ set of time periods (index $t$ );

I: $\quad$ set of items (index $i$ ).

Parameters:

$s c_{t}^{i}$ : $\quad$ setup cost of item $i$ in period $t$;

$v c_{t}^{i}$ : $\quad$ unit production cost of item $i$ in period $t$;

$h c_{t}^{i}$ : $\quad$ unit holding cost of item $i$ in period $t$;

$s t_{t}^{i}$ : $\quad$ setup time of item $i$ in period $t$;

$v t_{t}^{i}: \quad \quad$ unit production time of item $i$ in period $t$;

$d_{t}^{i}$ : demand of item $i$ in period $t$;

$s d_{t r}^{i}$ : $\quad$ sum of demands of item $i$ from period $t$ to period $r$;

$\mathrm{Cap}_{t}$ : capacity (time limit) available to produce the items in period $t$. 
Decision variables:

$X_{t}^{i}$ : $\quad$ production quantity of item $i$ in period $t$;

$S_{t}^{i}$ : $\quad$ inventory for item $i$ at the end of period $t$;

$Y_{t}^{i}$ : $\quad$ binary variable indicating the production or not of item $i$ in period $t$.

\section{Mathematical model for the CLSP}

$\min \sum_{t \in T} \sum_{i \in I}\left(s c_{t}^{i} Y_{t}^{i}+v c_{t}^{i} X_{t}^{i}+h c_{t}^{i} S_{t}^{i}\right)$

Subject to:

$S_{t-1}^{i}+X_{t}^{i}=d_{t}^{i}+S_{t}^{i}$

$\forall i, \forall t$

$X_{t}^{i} \leq s d_{t T}^{i} Y_{t}^{i}$

$\forall i, \forall t$

$\sum_{i \in I}\left(s t_{t}^{i} Y_{t}^{i}+v t_{t}^{i} X_{t}^{i}\right) \leq \operatorname{Cap}_{t}$

$\forall t$

$Y_{t}^{i} \in\{0,1\}$

$\forall i, \forall t$

$X_{t}^{i}, S_{t}^{i} \in \mathbb{R}_{+}$

$\forall i, \forall t$

The objective function (1) minimizes the total setup cost, production cost and inventory holding cost. Constraints (2) are the demand balance constraints: inventory carried over from the previous period and production in the current period are used to satisfy the current demand, and build up inventory that can be used in the next periods. Constraints (3) force the setup variable to one if any production takes place in the period. The next constraints (4) impose that the total production and setup time cannot exceed the available capacity in each period. Finally, constraints (5) and (6) are the integrality and non-negativity constraints.

The mathematical model presented for the CLSP represents a single level system, which corresponds to a problem in which the final products are obtained directly after being processed in a single operation. The corresponding demand for the final products is known as the independent demand. In a multi-level system, on the other hand, there is a relationship among the items described in the Bill-of-Material. Production of final products will trigger a demand for components, which represents the dependent demand. In the multi-level model, the demand balance constraint (2) is changed to distinguish between the dependent and independent demand. To formulate a multi-level problem we consider the following additional data:

$$
\begin{array}{ll}
S(i): & \text { set of direct successors of item } i \text { (index } l \text { ); } \\
r_{l}^{i}: & \text { number of items } i \text { used in one unit of item } l .
\end{array}
$$

Item $i$ can have its own independent demand as well as its dependent demand created by the production of its direct successors. We assume that an item can be both produced and consumed in the production of another (successor) item in the same time period, as is typically done for standard multi-level lot-sizing problems. However, it is possible to incorporate minimum lead times (see e.g. Pochet and Wolsey (2006), page 408). The new demand balance constraint is then written as:

$S_{t-1}^{i}+X_{t}^{i}=d_{t}^{i}+\sum_{l \in S(i)} r_{l}^{i} X_{t}^{l}+S_{t}^{i} \forall i, \forall t$

Among the various extensions of the lot-sizing problem we highlight the use of several machines to produce the items (Fiorotto \& de Araujo, 2014; Fiorotto, de Araujo, \& Jans, 2015; Jans, 2009; Toledo \& Armentano, 2006), as well as the possibility of backlogging some part of the demand (Gruson, Cordeau, \& Jans, 2017; Pochet \& Wolsey, 1988). The setup structure in the capacity constraint is another consideration that affects the problem complexity (Karimi et al., 2003). The setup of a product can be dependent or independent of the previous product in the production sequence (Guimarães, Klabjan, \& Almada-Lobo, 2014), or the final setup in a period can be carried over to the next period (Gopalakrishnan, Ding, Bourjolly, \& Mohan, 2001; Sahling, Buschkühl, Tempelmeier, \& Helber, 2009) or split between two periods (Fiorotto, Jans, \& de Araujo, 2017).

Alternative formulations for the lot-sizing problem have been proposed in the literature, for more details see Brahimi et al. (2006). We highlight the network reformulation proposed by Eppen and Martin (1987), which reformulates the lot-sizing problem as a shortest path problem, and the simple plant location reformulation proposed by Krarup and Bilde (1977). These reformulations are strong formulations, since they provide tighter lower bounds when compared with the original formulations. Extensions of these reformulations have been successfully applied to obtain further improved lower bounds (de Araujo \& Clark, 2013; de Araujo, de Reyck, Degraeve, Fragkos, \& Jans, 2015; Fiorotto et al., 2015; Jans \& Degraeve, 2004; Süral, Denizel, \& Wassenhove, 2009).

\subsection{Discussion of the cutting stock problem}

In this section, we consider the one-dimensional cutting stock problem, with only one type of object in stock, i.e., the onedimensional Single Stock Size Cutting Stock Problem (SSSCSP), as it has been defined in the typology of Wäscher et al. (2007). In this problem, a weakly heterogeneous assortment of small items is completely allocated to a selection of large objects of minimal value, number, or total size. The small items will be subsequently referred to as pieces. To model the SSSCSP, two formulations from the literature are considered. The first one is a compact formulation and has been attributed to Kantorovich (1960). This formulation is also known as the generalized assignment model for the CSP (Degraeve \& Peeters, 2003). Consider the following sets, parameters and decision variables:

Sets: $\quad \quad$ set of pieces (index $p$ ).
$P: \quad$

Parameters:

0 : $\quad$ upper bound on the number of objects needed;

$L: \quad$ object length;

$l_{p}: \quad$ length of piece $p$;

$d^{p}: \quad$ demand of piece $p$.

Decision variables:

$y_{0}$ : binary variable that indicates whether object $o$ is used or not;

$h_{0}^{p}$ : number of units of piece $p$ cut from object 0 .

Mathematical model for the SSSCSP (Kantorovich (1960))

$\min \sum_{o=1}^{O} y_{0}$

Subject to:

$\sum_{0=1}^{o} h_{o}^{p} \geq d^{p}$

$\sum_{p=1}^{P} l_{p} h_{o}^{p} \leq L y_{o}$

$\forall 0$

$y_{0} \in\{0,1\}$

$\forall 0$

$h_{o}^{p} \in \mathbb{Z}_{+} \quad \forall p, \forall 0$ 
The objective function (8) minimizes the number of cut objects. Constraints (9) ensure that the demand for each piece is satisfied. Constraints (10) are the knapsack constraints and guarantee that if object $o$ is cut, then the combination of the piece sizes that will be cut from it cannot exceed its size. Finally, the set of constraints (11) and (12) impose integrality and non-negativity conditions.

Next, we introduce the second model for the SSSCSP. This is probably the best known model for the cutting stock problem and was proposed by Gilmore and Gomory (1961, 1963). This formulation is more flexible when compared to Kantorovich's mathematical model in the sense that it can easily be adapted to take into account multi-dimensional problems and other extensions of the CSP. The formulation proposed by Gilmore and Gomory makes use of the idea of cutting patterns, which define the way that the pieces are cut from an object, while respecting the physical limitations of the object. Consider the following sets, parameters and decision variables:

$\begin{array}{ll}\text { Sets: } & \\ P: & \text { set of pieces (index } p \text { ). } \\ J: & \text { set of cutting patterns (index } j \text { ). }\end{array}$

$\begin{array}{ll}\text { Parameters: } & \\ a_{j}^{p}: & \text { number of times piece } p \text { is included in cutting pattern } j . \\ d^{p}: & \text { demand of piece } p .\end{array}$

Decision variables:

$Z_{j}$ : $\quad$ number of objects cut according to cutting pattern $j$.

Mathematical model for the SSSCSP (Gilmore \& Gomory (1961, 1963))

$\min \sum_{j=1}^{J} Z_{j}$

Subject to:

$\sum_{j=1}^{J} a_{j}^{p} Z_{j} \geq d^{p} \quad \forall p$

$Z_{j} \in \mathbb{Z}_{+}$

$\forall j$

The objective function (13) minimizes the number of cut objects. Constraints (14) ensure that the demand for each piece is met through the cutting of objects in stock using different cutting patterns. Constraints (15) are integrality constraints. Each solution of the model consists of a set of cutting patterns and their corresponding application frequencies.

Due to the large number of decision variables, this formulation becomes difficult to solve. For this reason, Gilmore and Gomory $(1961,1963,1965)$ proposed relaxing the integrality constraints and solving the resulting linear programming problem using a column generation technique. The $Z_{j}$ columns and associated parameters $a_{j}^{p}$ in (14) are generated by solving a subproblem and attractive columns are added to the master problem to improve the current solution. For the one-dimensional cutting stock problem, the subproblem is a regular knapsack problem (Gilmore \& Gomory, 1961,1963; Martello \& Toth, 1990). Considering higher dimensions for the subproblems, other solution methods have also been proposed in the literature (Arenales \& Morabito, 1995; Christofides \& Whitlock, 1977; Yanasse \& Katsurayama, 2005).

Typically, the solution of the relaxed problem is fractional and an integer solution can be obtained using heuristics based on the approximate fractional solution and rounding procedures (Poldi \& Arenales, 2009; Stadtler, 1990; Wäscher \& Gau, 1996) or by a branch-and-price procedure, which embeds a column generation process within a branch-and-bound approach (Alves \& Valério de Carvalho, 2008; Belov \& Scheithauer, 2006; Degraeve \& Peeters, 2003; Vance, Barnhart, Johnson, \& Nemhauser, 1994). Other alternative formulations for the cutting stock problem have been proposed, such as the one-cut-model of Dyckhoff (1981) and the arc flow model of Valério de Carvalho (1999, 2002).

The CSP in its standard form consists of determining how large objects can be cut into smaller pieces in order to meet the demand for the pieces. However, industrial cutting problems are often embedded in a production environment which is significantly different from the standard CSP. Consequently, over the years, the standard model has been extended to consider several different aspects found in industrial practice, which results in different features, constraints and objectives. Some extensions which will be of particular interest for this paper are described below.

The use of different types of objects (e. g. with different lengths, weights or thicknesses) is an important feature in some industries and can lead to a better overall material utilization. In general, the addition of costs associated with different objects is necessary. This results in other objective functions, such as minimizing the costs of the objects or the waste of material. When the costs of objects is proportional to the object length, a trim loss minimization arises (de Araujo, Constantino, \& Poldi, 2010; Belov \& Scheithauer, 2002). With the addition of different objects, establishing an optimal solution for this problem becomes more difficult. The objects may be available in an unlimited quantity (Valério de Carvalho, 2002; Furini \& Malaguti, 2013) or may be subject to an upper bound level (Belov \& Scheithauer, 2002; Poldi \& Arenales, 2009). In some cases, the non-used material in the cutting patterns does not necessarily become a waste of material. If its size is large enough, the raw material can be stored in the warehouse to be used later as input in the cutting process to produce other pieces (Andrade, Birgin, Morabito, \& Ronconi, 2014; Arbib, Marinelli, Rossi, \& Iorio, 2002; Cherri, Arenales, Yanasse, Poldi, \& Vianna, 2014).

In the extensions discussed up to now, the raw material cost has a huge impact on the cutting stock problem. However, in some industrial applications such as in the paper industry, the raw material has a low value per unit, whereas several complex processing operations are required to obtain the final products. In such a case, it is typically inappropriate to define the decision criterion as the minimization of trim loss or objects costs and a more realistic criterion is the minimization of other control costs (Haessler, 1975). An important case is the incorporation of costs associated with the use of a new cutting pattern different from the previous one, since a setup is necessary whenever a new cutting pattern is started and the cutting equipment has to be prepared for this new cutting pattern. Setups of this kind involve the loss of production time capacity, additional costs and consumption of resources. In such cases, the minimization of setup cost is added to the minimization of objects or waste costs (Diegel, Montocchio, Walters, van Schalkwyk, \& Naidoo, 1996; Haessler, 1975; Vanderbeck, 2000).

To model a setup constraint in the formulation proposed by Gilmore and Gomory (1961, 1963), we first define $W_{j}$ as a binary variable indicating if cutting pattern $j$ is used or not and $M$ as a large number. The following constraints can be added to the model:

$$
Z_{j} \leq M W_{j} \forall j
$$

Constraints (16) ensures that a cutting pattern setup is done whenever a cutting pattern is used at least once. In some cases, the number of cutting patterns is minimized (Vanderbeck, 2000). In other cases, a limit is imposed on the number of cutting pattern setups, while optimizing some other objective, such as the deviation from the demand (Umetani, Yagiura, \& Ibaraki, 2003) or the minimization of the number of objects used (Umetani, Yagiura, \& Ibaraki, 2006). Other approaches first optimize a regular 


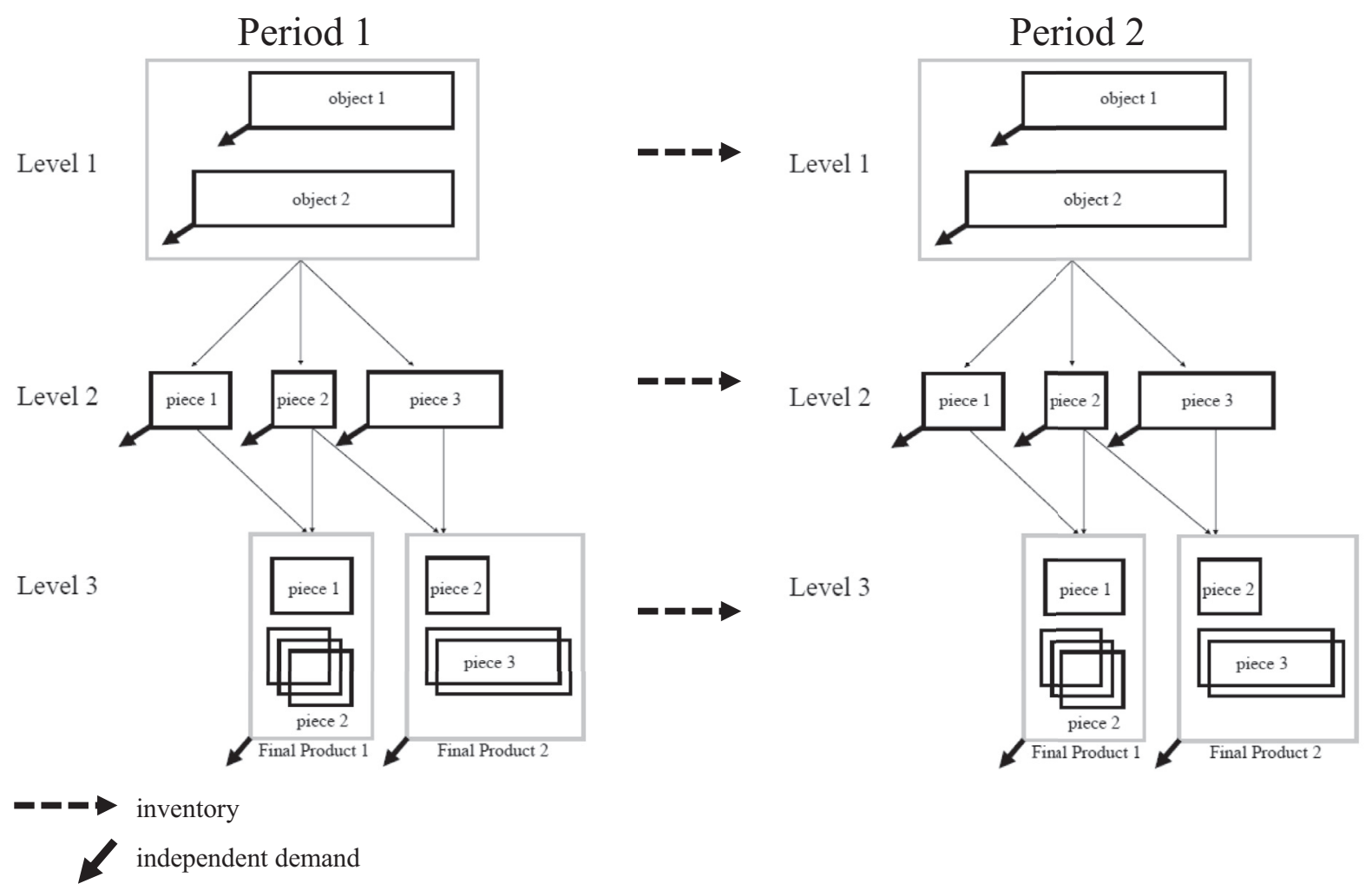

Fig. 1. Integration between three production levels and two time periods.

objective such as the minimization of the number of objects used or the waste, and next find a solution that minimizes the number of cutting patterns used (Cui, Zhong, \& Yao, 2015; Foerster \& Wäscher, 2000; Yanasse \& Limeira, 2006). Some papers also consider a multi-objective problem (de Araujo, Poldi, \& Smith, 2014; Golfeto, Moretti, \& de Salles Neto, 2009). A literature review on the cutting stock problem with setups can be found in Henn and Wäscher (2013).

\subsection{A generalized integrated problem}

A generalized 3-level integrated lot-sizing and cutting stock (G3ILSCS) model is proposed with the purpose of discussing and classifying the papers in the literature that address both problems simultaneously or are closely related to this integrated problem. We consider a deterministic setting and a production environment composed of three levels (see Fig. 1), where objects are acquired and next cut into pieces. These pieces form the input for the assembly process, in which final products are made. The generalized integrated model is based on the model proposed by Trigeiro et al. (1989) and on the model proposed by Gilmore and Gomory (1961,1963,1965), to model the LSP and CSP, respectively.

Level 1 corresponds to the planning of the acquisition of the objects which will be cut in pieces. This can be done either by internal production or by ordering from an outside supplier. The objects may differ in size. Level 2 corresponds to the cutting process, in which the objects are cut into pieces through the use of cutting patterns. The pieces can be used as components for the assembly of final products or they can be directly considered as the final products which still need to undergo some finishing process. The production of the final products is modeled at level 3. In most of the cases a final product requires more than one type of piece as a component. There is an independent demand for the final products, which will trigger a dependent demand for pieces and objects. We assume that, apart from final products, also pieces and objects may have independent demand. The need for integrating the three levels can be seen clearly in some practical application. For instance in the furniture industry, wooden plates are produced or purchased from different suppliers (level 1), and then cut into several wooden parts (level 2) to be assembled into the final products, for example, a wardrobe (level 3). Such a type of problem has a multi-level structure and the benefits of considering an integrated approach instead of taking decisions separately, have been demonstrated in the literature.

Fig. 1 also shows a second type of integration, i.e., among different time periods. Indeed, the integrated model is a dynamic model where multiple periods are considered simultaneously, whereas the standard cutting stock model is a one-period model. This dynamic aspect is shown in Fig. 1, which presents an integrated problem with three levels and two time periods. Note that the figure is restricted to only two time periods in order not to complicate the presentation. In each period, we have independent demand for the final products and possibly for the cut pieces and objects as well. The link between the different periods is provided by the inventory which can be carried over from one period to the next. We can keep inventory for the final products, for the cut pieces and for the objects. Demand must be satisfied either from production in the current period or from inventory carried over from the previous period.

Consider the following sets, parameters and decision variables for the generalized 3-level model:

Sets:

$T$ : set of time periods (index $t$ );

$O=\{1, \ldots, l\}$ : set of different types of objects (index 0 );

$P=\{l+1, \ldots, l+m\}$ : set of pieces (index $p$ );

$F=\{l+m+1, \ldots, l+m+n\}$ : set of final products (index $f$ );

$J_{o}$ : set of cutting patterns for object type $o$ (index $j$ ). 
Parameters:

$\begin{array}{ll}s c_{t}^{0}: & \text { setup cost/fixed ordering cost for object type } o \text { in period } t ; \\ v c_{t}^{0}: & \text { unit production cost/purchase cost of object type } o \text { in period } t ; \\ h c_{t}^{0}: & \text { unit holding cost of object type } o \text { in period } t ; \\ d_{t}^{o}: & \text { independent demand of object type } o \text { in period } t ; \\ s t_{t}^{0}: & \text { setup time for object type } o \text { in period } t ; \\ v t_{t}^{0}: & \text { unit production time of object type } o \text { in period } t ; \\ \text { CapO }_{t}: & \text { production capacity (in time units) available to produce the } \\ & \text { objects in period } t ; \\ u_{j}^{o}: & \text { setup cost for cutting pattern } j \text { for object type } o ; \\ c_{j}^{0}: & \text { cost of cutting an object type } o \text { according to cutting pattern } j ; \\ h c_{t}^{p}: & \text { unit holding cost of piece } p \text { in period } t ; \\ d_{t}^{p}: & \text { independent demand of piece } p \text { in period } t ; \\ r_{f}^{p}: & \text { number of pieces of type } p \text { required in the final product } f ; \\ a_{o j}^{p}: & \text { number of pieces } p \text { cut from object type } o \text { using the cutting } \\ s t_{j t}^{o}: & \text { pattern } j ; \\ v t_{j t}^{o}: & \text { setup time of the object type } o \text { cut according to cutting pattern } \\ \text { CapP }: & j \text { in period } t ; \\ & \text { production time to cut object type } o \text { according to cutting }\end{array}$

$s c_{t}^{f}: \quad \quad$ setup cost of final product $f$ in period $t$;

$v c_{t}^{f}: \quad \quad \quad$ unit production cost of final product $f$ in period $t$;

$h c_{t}^{f}: \quad \quad \quad$ unit holding cost of final product $f$ in period $t$;

$s t_{t}^{f}$ : $\quad$ setup time of final product $f$ in period $t$;

$v t_{t}^{f}: \quad \quad \quad$ unit production time of final product $f$ in period $t$;

$d_{t}^{f}: \quad \quad$ demand of final product $f$ in period $t$;

$s d_{t r}^{f}: \quad \quad \quad$ sum of demand of final product $f$ from period $t$ until period $r$;

CapF $_{t}$ : production capacity (in time units) available to produce the final products in period $t$;

M: $\quad$ large number.

Decision variables:

$X_{t}^{o}: \quad$ production/purchase quantity of object $o$ in period $t$;

$S_{t}^{o}: \quad$ inventory of object $o$ at the end of period $t$;

$Y_{t}^{o}$ : $\quad$ binary variable indicating the production/purchase or not of object $o$ in period $t$;

$X_{t}^{p}$ : production quantity of piece $p$ in period $t$;

$S_{t}^{p}$ : inventory of piece $p$ at the end of period $t$;

$Z_{j t}^{o}$ : number of objects of type $o$ cut according to cutting pattern $j$ in period $t$;

$W_{j t}^{o}$ : binary variable indicating the setup or not of cutting pattern $j$ for object type $o$ in period $t$;

$X_{t}^{f}: \quad$ production quantity of final product $f$ in period $t$;

$S_{t}^{f}: \quad$ inventory of final product $f$ at the end of period $t$;

$Y_{t}^{f}$ : binary variable indicating the setup or not of final product $f$ in period $t$.

The generalized 3-level integrated model is as follows:

Model G3ILSCS

$$
\begin{aligned}
\min & \sum_{t \in T}\left(\sum_{o \in O}\left(s c_{t}^{o} Y_{t}^{o}+v c_{t}^{o} X_{t}^{o}+h c_{t}^{o} S_{t}^{o}\right)+\sum_{o \in O} \sum_{j \in J}\left(u_{j}^{o} W_{j t}^{o}+c_{j}^{o} Z_{j t}^{o}\right)\right. \\
+ & \left.\sum_{p \in P} h c_{t}^{p} S_{t}^{p}+\sum_{f \in F}\left(s c_{t}^{f} Y_{t}^{f}+v c_{t}^{f} X_{t}^{f}+h c_{t}^{f} S_{t}^{f}\right)\right)
\end{aligned}
$$

Subject to:

$$
\begin{array}{lr}
S_{t-1}^{f}+X_{t}^{f}=d_{t}^{f}+S_{t}^{f} & \forall f, \forall t \\
X_{t}^{f} \leq s d_{t T}^{f} Y_{t}^{f} & \forall f, \forall t \\
\sum_{f \in F}\left(s t_{t}^{f} Y_{t}^{f}+v t_{t}^{f} X_{t}^{f}\right) \leq C a p F_{t} & \forall t \\
S_{t-1}^{p}+X_{t}^{p}=\sum_{f \in F} r_{f}^{p} X_{t}^{f}+d_{t}^{p}+S_{t}^{p} & \forall p, \forall t \\
X_{t}^{p}=\sum_{o \in O} \sum_{j \in J_{o}} a_{o j}^{p} Z_{j t}^{o} & \forall p, \forall t
\end{array}
$$

$$
\begin{array}{lr}
Z_{j t}^{o} \leq M W_{j t}^{o} \forall j, & \forall o, \forall t \\
\sum_{o \in O} \sum_{j \in J_{o}}\left(s t_{j t}^{o} W_{j t}^{o}+v t_{j t}^{o} Z_{j t}^{o}\right) \leq C a p P_{t} & \forall t \\
S_{t-1}^{o}+X_{t}^{o}=\sum_{j \in J_{o}} Z_{j t}^{o}+d_{t}^{o}+S_{t}^{o} & \forall 0, \forall t \\
X_{t}^{o} \leq M Y_{t}^{o} \forall o, & \forall t \\
\sum_{o \in O}\left(s t_{t}^{o} Y_{t}^{o}+v t_{t}^{o} X_{t}^{o}\right) \leq \operatorname{CapO}_{t} & \forall t \\
X_{t}^{o}, S_{t}^{o} \geq 0, Y_{t}^{o} \in\{0,1\} & \forall 0, \forall t \\
X_{t}^{p}, S_{t}^{p} \geq 0, Z_{j t}^{o} \in \mathbb{Z}_{+}, W_{j t}^{o} \in\{0,1\} & \forall p, \forall j, \forall 0, \forall t \\
X_{t}^{f}, S_{t}^{f} \geq 0, Y_{t}^{f} \in\{0,1\} & \forall f, \forall t
\end{array}
$$

The objective function (17) minimizes the overall costs at each level. At level 1, the costs are related to the objects and include the fixed setup (or ordering) cost for the production (or purchase) of objects, their production (or purchasing) cost and their inventory holding cost. At level 2, the costs refer to the cutting process. At this level, we take into account the setup cost of a cutting pattern, the cost of cutting an object according to a cutting pattern and the cost of holding the pieces in inventory. The last terms in the objective function correspond to the setup, production and inventory costs of final products at level 3 .

Constraints (18)-(20) refer to the final products and jointly with constraints (30) can be seen as a lot-sizing problem at level 3. Constraints (18) are the demand balance constraints for the final products. Constraints (19) force the setup variable to one if any production takes place in that period. Constraint (20) imposes the capacity limits of the production process for final products. We can apply stronger reformulations for the lot-sizing problem at level 3 without any difficulty. For the sake of simplicity and brevity, we only present the formulation with the standard lot-sizing variables.

Constraints (21)-(24) and (29) are related to the production of the cut pieces and can be seen as a multi-period cutting stock problem with capacity constraints at level 2 . Constraint (21) ensures that the dependent demand $\left(\sum_{f \in F} r_{f}^{p} X_{t}^{f}\right)$ and the independent demand $\left(d_{t}^{p}\right)$ for pieces is satisfied. This constraint also models the interdependency between the decisions of level 2 and level 3 and corresponds to an integration between the levels of the CSP and LSP. Constraint (22) is a definition constraint and defines the number of pieces of type $p$ cut in period $t$ as a function of the selected cutting patterns. Note that the variable $X_{t}^{p}$ in constraint (21) can be replaced by $\sum_{o \in O} \sum_{j \in J_{o}} a_{o j}^{p} Z_{j t}^{o}$ according to the definition constraint (22). Constraint (23) forces a pattern setup in the cutting machine, whenever an object is cut according to a new cutting pattern. The setup addressed in this paper is independent from the preceding cutting pattern. The capacity constraint (24) considers the use of only one machine in the cutting process and takes into account the time consumed for setting up the cutting patterns, as well as the time for cutting the objects according to a specific pattern.

Constraints (25)-(28) model a lot-sizing problem at level 1 with both dependent and independent demand. Constraint (25) is the demand balance constraint for objects at level 1. This constraint also links level 1 and level 2 ensuring the production (or purchase) of a sufficient number of objects needed in the cutting process and corresponds to another integration between the levels of the LSP and CSP. Constraint (26) is the setup forcing constraint related to the production of objects. The capacity limit for the production of objects is modeled by constraint (27). The time spent to set up 
the machine for a specific object type and to produce the objects consumes the capacity available. Note that if the objects are purchased from a supplier instead of internally produced, there is no such capacity constraint. Finally, (28)-(30) are the non-negativity and integrality constraints for the G3ILSCS model.

Some remarks related to the generalized 3-level integrated problem are necessary before using this model as a tool for classifying the current literature:

- The CSP embedded in level 2 of our proposed model can be considered as an extension of the one-dimensional Multiple Stock Size Cutting Stock Problem (MSSCSP, using the typology proposed by Wäscher et al. (2007)) to a multi-period setting. Moreover, the CSP at level 2 considers both independent and dependent demand since it is embedded in a multi-level structure. The LSPs embedded in level 1 and level 2 are the wellknown Capacitated Lot-Sizing Problems (CLSP). At level 3, there is only an independent demand for the final products, whereas at level 1 , we have both dependent and independent demand for the objects because of the dependencies in a multi-level structure. In the proposed model, the setup cost and time, as well as the capacities, are considered independent for each level.

- The motivation to choose the formulation proposed by Gilmore and Gomory to model the cutting stock problem is mainly due to the flexibility of this formulation. More specifically, it allows the consideration of setup costs and setup times related to the cutting pattern, as well as a specific cost and time related to the cutting of an object according to a specific pattern. The models of Dyckhoff (1981) and Valério de Carvalho $(1999,2002)$ are less suitable for extensions that include setup aspects (Henn \& Wäscher, 2013). Another flexible aspect of the formulation proposed by Gilmore and Gomory is the generation of the cutting patterns through the solution of a subproblem. As a consequence, the formulation itself does not need to specify the dimensionality of the problem, which contributes to its use in different industrial applications, which is not the case for other formulations.

- In lot-sizing models, the setup cost should only reflect the direct costs related to a setup. This setup cost should, however, not include a penalty cost for lost capacity, since this should be taken into account via the introduction of setup times in the capacity constraint. The direct setup cost could be related, for example, to the fact that at the beginning of a batch some items need to be discarded due to quality issues. Süral et al. (2009) discuss this in more detail, and consider problems that only consider setup times and no setup cost. In order to keep the model as flexible as possible, we consider both setup times and setup costs in our model.

- Analyzing the lot-sizing literature with respect to the consideration of dynamic or constant costs in the objective function, we observe that some papers consider dynamic costs which can lead to speculative motives (see e.g. Pochet \& Wolsey (2006)). In spite of presenting the mathematical model with dynamic costs, some of the papers consider these costs as constant parameters in the computational results. As we intend to propose a generalized model that covers different practical cases, we kept dynamic costs in the generalized model.

- In multi-level lot-sizing problems (see constraints (21) and (25)) a lead-time offset of at least one period can be incorporated to allow the disaggregation into a machine schedule (Almeder (2010)). However, as none of the papers on the integrated lot-sizing and cutting stock problem consider lead-times, and as this model will be used to classify the literature, we decide to keep constraints (21) and (25) without lead-time. Ob-
Table 1

Framework for classifying the papers from literature.

\begin{tabular}{llll}
\hline & & \multicolumn{2}{l}{ Integration between production levels } \\
\cline { 3 - 4 } & & No & Yes \\
\hline \multirow{3}{*}{$\begin{array}{lll}\text { Integration } \\
\text { across times }\end{array}$} & No & Cutting stock problem & $\begin{array}{l}\text { Single-period multi-level production } \\
\text { and cutting stock problems } \\
\text { periods }\end{array}$ \\
\cline { 2 - 4 } & & $-/ L 2 /-/ S$ & $L 1 / L 2 /-/ S-/ L 2 / L 3 / S L 1 / L 2 / L 3 / S$ \\
& & Multi-period & Integrated lot-sizing and \\
& Yes & cutting stock problem & cutting stock problem \\
& & $-/ L 2 /-/ M$ & $L 1 / L 2 /-/ M-/ L 2 / L 3 / M L 1 / L 2 / L 3 / M$ \\
\hline
\end{tabular}

serve that it is possible to adapt the proposed model in order to consider lead-times (Pochet and Wolsey (2006), page 408).

- In theory, a more general model could be proposed considering other aspects of the production process, such as, sequencedependent setups, usable leftovers, backorders, or an assembly structure where some components are made in a regular (noncutting) manufacturing process. However, as one of the aims of this model is to allow a clear classification of the literature, instead of aiming to provide a more general model that includes various side constraints, we decided to keep the model simpler and to focus on the relevant levels that appeared in the literature.

\section{A classification and discussion of the literature}

In this section, a literature review of the integrated lot-sizing and cutting stock problem is carried out using classification criteria based on various aspects of the newly proposed generalized 3-level integrated model (G3ILSCS). Some related problems are also considered in our literature review. It is worth noticing that our aim is to propose a high-level classification of the literature, focusing mainly on the integration between the problems. Some details of each individual problem are also presented and discussed, but this is not the main focus of our classification.

\subsection{Classification criteria}

In this literature review, we restrict our analysis to studies which are publicly available and have been published in English in international journals, technical reports, and conference proceedings. We classified 34 papers in total and half of the papers (17/34), covering this topic, are from 2011 onwards. Just in the last two years 9 new papers have been published. This shows the increasing interest in this topic (see Fig. 2).

The models from the literature are analyzed and classified according to two main aspects. The first is the integration between production levels (see Fig. 1). A model is classified at a specific level $(1,2$ and 3$)$ if there is a decision variable (production, setup or inventory variable) associated with this level. The second main criterion is related to the integration across multiple time periods (see Fig. 1), which comes from the possibility to hold items in stock, i.e., there is an inventory variable linking the periods. Based on these two aspects we introduce a four-field notation * $\left.\right|^{*}|*|^{*}$. The first, second and third field can receive, respectively, "L1", "L2" and " $L 3$ ", meaning that a decision variable is considered at the respective level. When a specific level is not considered, its field will remain empty (indicated by a "-"). The fourth field receives the letter " $S$ " or " $M$ ", and represents the classification of the cutting stock problem as single period ("S") or multiperiod ("M"), respectively.

Considering this notation we have classified and divided the papers from the literature in four main sets and some subsets. Table 1 shows the main ideas of this categorization.

- The first quadrant represents the base case which is the standard single-period cutting stock problem. Papers considering this case are not discussed in this review paper. 


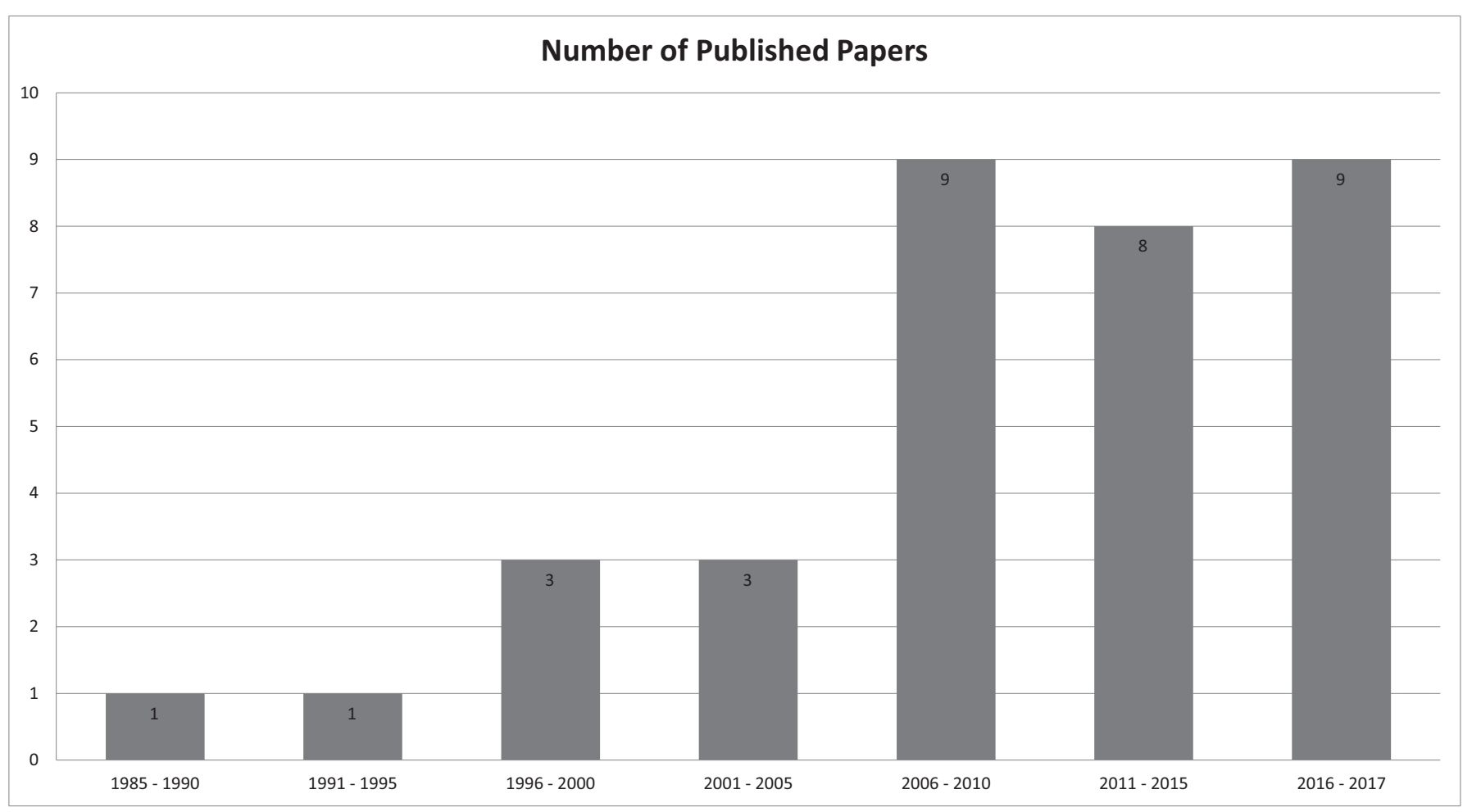

Fig. 2. Number of published papers on integrated problems.

- To be considered an Integrated Lot-Sizing and Cutting Stock Problem (see Table 1), it is necessary to consider the two aspects of integration, i.e., integration between at least two production levels and integration across time periods. We have found a set of 25 papers with these characteristics which are divided into three subsets.

- L1/L2/ - /M: We found 13 papers that consider the integration between the lot-sizing problem regarding the planning of the acquisition of the objects (level 1) and the multiperiod cutting stock problem at level 2.

- $-/ L 2 / L 3 / M$ : 9 papers consider the integration between the multi-period cutting stock problem at level 2 and the lotsizing problem for final products at level 3. Pieces cut at level 2 are used to assemble the final product at level 3.

- L1/L2/L3/M: Only 3 papers consider the integration between the three production levels in a multi-period production setting.

- We found 2 papers in the literature that consider the integration between production levels, but do not consider the integration across time periods, i.e., they consider a single period of production. Consequently, they are not classified as integrated lot-sizing and cutting stock problem. It is worth noticing that the use of the term lot-sizing is not adequate in this case, since there is only a single period of production. As shown in Table 1 we classify these models as Single-Period Multi-Level Production and Cutting Stock Problems.

- L1/L2/ - /S: One of the papers (Silva, Viães, Oliveira, \& Carravilla (2015)) considers the integration between the production at level 1 and the standard single-period cutting stock problem at level 2 .

- - L2/L3/S: The other one (Farley (1988)) considers the integration between the single-period cutting stock problem at level 2 and the production of final products at level 3 .

- $-/ L 2 /-/ M$ : The final set is composed of 4 papers that consider the integration across time periods but not between production levels. The standard cutting stock problem only considers one period, and hence there is no possibility to keep inventory. The pieces which are left at the end of the single period are considered as waste. The papers that belong to this set extend the standard cutting stock problems by considering a multi-period setting at level 2 . Instead of classifying these papers as integrated lot-sizing and cutting stock problem, we prefer to use the term Multi-Period Cutting Stock Problem (see Table 1).

We observe that the proposed classification allows to distinguish the concept of a multi-period cutting stock problem and an integrated lot-sizing and cutting stock problem based on the dimensions of production levels and time periods.

This classification can be directly related to the characteristics present in our generalized 3-level integrated model and these relations are presented in Table 2 . The proposed classification is detailed in the first two columns of the table and, in the remaining columns, the correspondence with the generalized integrated model is presented, considering time periods, constraints and variables. For sake of simplicity we omitted the objective function in this table. When there is no integration across time periods, this corresponds to the case where $|T|=1$. For models where there is integration across time periods this is equivalent to the case where $|T|>1$. The integrations between production levels is classified in the last two columns presenting the constraints and the variables related to that level.

We have found 3 papers in the literature that consider integrated (or related) problems, but they assume an infinite planning horizon and continuous time model, with a constant demand rate. These characteristics do not fit in our proposed model which has a finite planning horizon with discrete time periods. For this reason, we will not include these paper in the tables presented in the next section, but we will discuss them separately.

Table 3 shows the classification of the papers found in the literature according to the new framework presented in Table 1, while Section 3.2 presents a detailed discussion. Since most of the current research in this area is based on practical applications, 
Table 2

Correspondence of the classification in the generalized 3-level integrated model.

\begin{tabular}{|c|c|c|c|c|}
\hline \multirow[t]{2}{*}{ Types of integration } & \multirow[t]{2}{*}{ Levels of integration } & \multicolumn{3}{|c|}{ Generalized 3-level integrated model } \\
\hline & & Time periods & Constraints & Variables \\
\hline \multirow[t]{3}{*}{$\begin{array}{l}\text { Multi-level and } \\
\text { multi-period }\end{array}$} & $\begin{array}{l}\text { Levels } 1 \text { and } 2 \\
\text { L1/L2/-/M }\end{array}$ & $|T|>1$ & $\begin{array}{l}(21),(22),(23),(24),(25) \\
(26) \text { and }(27)\end{array}$ & $\begin{array}{l}X_{t}^{o}, S_{t}^{o} \geq 0, Y_{t}^{o} \in\{0,1\} \\
X_{t}^{p}, S_{t}^{p} \geq 0, Z_{j t}^{o} \in \mathbb{Z}_{+}, W_{j t}^{o} \in\{0,1\} \\
X_{t}^{f}=0\end{array}$ \\
\hline & $\begin{array}{l}\text { Levels } 2 \text { and } 3 \\
-/ \mathrm{L} 2 / \mathrm{L} 3 / \mathrm{M}\end{array}$ & $|T|>1$ & $\begin{array}{l}\text { (18), (19), (20), (21), (22), } \\
\text { (23) and (24) }\end{array}$ & $\begin{array}{l}X_{t}^{p}, S_{t}^{p} \geq 0, \quad Z_{j t}^{o} \in \mathbb{Z}_{+}, W_{j t}^{o} \in\{0,1\} \\
X_{t}^{f}, S_{t}^{f} \geq 0, \quad Y_{t}^{f} \in\{0,1\}\end{array}$ \\
\hline & $\begin{array}{l}\text { Levels } 1,2 \text { and } 3 \\
\text { L1/L2/L3/M }\end{array}$ & $|T|>1$ & $\begin{array}{l}\text { (18), (19), (20), (21), (22), } \\
(23),(24),(25),(26) \text { and (27) }\end{array}$ & $\begin{array}{l}X_{t}^{o}, S_{t}^{o} \geq 0, Y_{t}^{o} \in\{0,1\} \\
X_{t}^{p}, S_{t}^{p} \geq 0, Z_{j t}^{o} \in \mathbb{Z}_{+}, W_{j t}^{o} \in\{0,1\} \\
X_{t}^{f}, S_{t}^{f} \geq 0, Y_{t}^{f} \in\{0,1\}\end{array}$ \\
\hline \multirow[t]{2}{*}{$\begin{array}{l}\text { Multi-level and } \\
\text { single-period }\end{array}$} & $\begin{array}{l}\text { Levels } 1 \text { and } 2 \\
\text { L1/L2/-/S }\end{array}$ & $|T|=1$ & $\begin{array}{l}(21),(22),(23),(24),(25) \\
(26) \text { and }(27)\end{array}$ & $\begin{array}{l}X_{t}^{o} \geq 0, Y_{t}^{o} \in\{0,1\} \\
X_{t}^{p} \geq 0, Z_{j t}^{o} \in \mathbb{Z}_{+}, W_{j t}^{o} \in\{0,1\} \\
X_{t}^{f}=0\end{array}$ \\
\hline & $\begin{array}{l}\text { Levels } 2 \text { and } 3 \\
-/ \text { L2/L3/S }\end{array}$ & $|T|=1$ & $\begin{array}{l}\text { (18), (19), (20), (21), (22), } \\
(23) \text { and (24) }\end{array}$ & $\begin{array}{l}X_{t}^{p} \geq 0, Z_{j t}^{o} \in \mathbb{Z}_{+}, W_{j t}^{o} \in\{0,1\} \\
X_{t}^{f} \geq 0, Y_{t}^{f} \in\{0,1\}\end{array}$ \\
\hline $\begin{array}{l}\text { Single-level and } \\
\text { multi-period }\end{array}$ & $\begin{array}{l}\text { Level } 2 \\
-/ \mathrm{L} 2 /-/ \mathrm{M}\end{array}$ & $|T|>1$ & (21), (22), (23) and (24) & $\begin{array}{l}X_{t}^{p}, S_{t}^{p} \geq 0, Z_{j t}^{o} \in \mathbb{Z}_{+}, W_{j t}^{o} \in\{0,1\} \\
X_{t}^{f}=0\end{array}$ \\
\hline
\end{tabular}

Table 3

Classification according to the time dimension and production levels.

\begin{tabular}{|c|c|c|c|c|c|c|c|}
\hline \multirow{2}{*}{$\begin{array}{l}\text { Types of } \\
\text { integration }\end{array}$} & \multirow{2}{*}{$\begin{array}{l}\text { Levels of } \\
\text { integration }\end{array}$} & \multirow[b]{2}{*}{ Papers } & \multirow{2}{*}{$\begin{array}{l}\text { Time } \\
\text { periods }\end{array}$} & \multicolumn{3}{|c|}{ Decision levels } & \multirow[b]{2}{*}{ Application } \\
\hline & & & & Level 1 & Level 2 & $\overline{\text { Level } 3}$ & \\
\hline \multirow{24}{*}{$\begin{array}{l}\text { Multi-level } \\
\text { and } \\
\text { multi-period }\end{array}$} & \multirow{12}{*}{$\begin{array}{l}\text { Levels } 1 \text { and } 2 \\
\text { L1/L2/-/M }\end{array}$} & Agostinho et al. (2016) & Multiple & $\checkmark$ & $\checkmark$ & - & General \\
\hline & & Campello et al. (2017) & Multiple & $\checkmark$ & $\checkmark$ & - & Paper \\
\hline & & Correia et al. (2004) & Multiple & $\checkmark$ & $\checkmark(2)$ & - & Paper \\
\hline & & Hendry et al. (1996) & Multiple & $\checkmark$ & $\checkmark$ & - & Copper \\
\hline & & Leão and Toledo (2016) & Multiple & $\checkmark$ & $\checkmark$ & - & Paper \\
\hline & & Malik et al. (2009) & Multiple & $\checkmark$ & $\checkmark$ & - & Paper \\
\hline & & Poldi and de Araujo (2016) & Multiple & $\checkmark$ & $\checkmark$ & - & Paper \\
\hline & & Poltroniere et al. (2016, 2008) & Multiple & $\checkmark$ & $\checkmark$ & - & Paper \\
\hline & & Reinders (1992) & Multiple & $\checkmark$ & $\checkmark(2)$ & - & Wood \\
\hline & & Silva et al. (2014) & Multiple & $\checkmark$ & $\checkmark$ & - & Furniture \\
\hline & & Trkman and Gradisar (2007) & Multiple & $\checkmark$ & $\checkmark$ & - & General \\
\hline & & Viegas et al. (2016) & Multiple & $\checkmark$ & $\checkmark$ & - & Steel \\
\hline & \multirow{9}{*}{$\begin{array}{l}\text { Levels } 2 \text { and } 3 \\
-/ \mathrm{L} 2 / \mathrm{L} 3 / \mathrm{M}\end{array}$} & Alem and Morabito (2012) & Multiple & - & $\checkmark$ & $\checkmark$ & Furniture \\
\hline & & Alem and Morabito (2013) & Multiple & - & $\checkmark$ & $\checkmark$ & Furniture \\
\hline & & Ghidini et al. (2007) & Multiple* & - & $\checkmark$ & $\checkmark$ & Furniture \\
\hline & & Gramani et al. (2009) & Multiple & - & $\checkmark$ & $\checkmark$ & Furniture \\
\hline & & Gramani et al. (2011) & Multiple & - & $\checkmark$ & $\checkmark$ & Furniture \\
\hline & & Santos et al. (2011) & Multiple* & - & $\checkmark$ & $\checkmark$ & Furniture \\
\hline & & Suliman (2012) & Multiple & - & $\checkmark$ & $\checkmark$ & Aluminium \\
\hline & & Vanzela et al. (2017) & Multiple & - & $\checkmark$ & $\checkmark$ & Furniture \\
\hline & & Wu et al. (2017) & Multiple & - & $\checkmark$ & $\checkmark$ & General \\
\hline & \multirow{3}{*}{$\begin{array}{l}\text { Levels } 1,2 \text { and } 3 \\
\text { L1/L2/L3/M }\end{array}$} & Arbib and Marinelli (2005) & Multiple & $\checkmark$ & $\checkmark$ & $\checkmark$ & Gear Belts \\
\hline & & Melega et al. (2016) & Multiple & $\checkmark$ & $\checkmark$ & $\checkmark$ & General \\
\hline & & Ouhimmou et al. (2008) & Multiple & $\checkmark$ & $\checkmark$ & $\checkmark$ & Wood \\
\hline \multirow[t]{2}{*}{$\begin{array}{l}\text { Multi-level } \\
\text { and single-period }\end{array}$} & $\begin{array}{l}\text { Levels } 1 \text { and } 2 \\
\text { L1/L2/-/S }\end{array}$ & Silva et al. (2015) & Single & $\checkmark$ & $\checkmark$ & - & Textile \\
\hline & $\begin{array}{l}\text { Levels } 2 \text { and } 3 \\
-/ \mathrm{L} 2 / \mathrm{L} 3 / \mathrm{S}\end{array}$ & Farley (1988) & Single & - & $\checkmark$ & $\checkmark$ & Textile \\
\hline \multirow{4}{*}{$\begin{array}{l}\text { Single-level } \\
\text { and } \\
\text { multi-period }\end{array}$} & \multirow{4}{*}{$\begin{array}{l}\text { Level } 2 \\
-/ \mathrm{L} 2 /-/ \mathrm{M}\end{array}$} & Aktin and Özdemir (2009) & Multiple & - & $\checkmark$ & - & Medicine \\
\hline & & Gramani and França (2006) & Multiple & - & $\checkmark$ & - & Furniture \\
\hline & & Prata et al. (2015) & Multiple & - & $\checkmark$ & - & Concrete \\
\hline & & Respício and Captivo (2002) & Multiple & - & $\checkmark$ & - & Paper \\
\hline
\end{tabular}

(2) Indicates two sub-levels. $\left({ }^{*}\right)$ Use of sub-periods

Table 3 also provides information on the type of industry in which the model is used. Once classified according to the two main axes of integration, i.e., between production levels and across time periods, other features such as capacity and setups are further analyzed in Section 3.3. Several aspects with respect to the three types of products (objects, pieces and final products) are also discussed. Tables 4 and 5 show a summary of these further operational aspects.

\subsection{Classification and discussion}

In the literature, the term "integrated lot-sizing and cutting stock model" can refer to many different types and degrees of integration. As discussed, the main types of integration which we observe are the integration between production levels and the integration across time periods. In Table 3, with respect to the integration between production levels, we indicate which 
Table 4

Further operational aspects.

\begin{tabular}{|c|c|c|c|c|c|c|}
\hline $\begin{array}{l}\text { Types of } \\
\text { integration }\end{array}$ & $\begin{array}{l}\text { Levels of } \\
\text { integration }\end{array}$ & Papers & Dimensionality & Objects & Pieces & Final products \\
\hline \multirow[t]{26}{*}{$\begin{array}{l}\text { Multi-level and } \\
\text { multi-period }\end{array}$} & \multirow[t]{13}{*}{$\begin{array}{l}\text { Levels } 1 \text { and } 2 \\
\text { L1/L2/-/M }\end{array}$} & Agostinho et al. (2016) & One-dimensional & $\begin{array}{l}\text { Several types (lengths) } \\
\text { inventory / leftover } \\
\text { (limited) } \\
\text { objects and leftover } \\
\text { availability }\end{array}$ & Inventory & - \\
\hline & & Campello et al. (2017) & One-dimensional & $\begin{array}{l}\text { Several types (grades) / } \\
\text { inventory }\end{array}$ & Inventory & - \\
\hline & & Correia et al. (2004) & One/two-dimensional & $\begin{array}{l}\text { Several types (grades) / } \\
\text { no inventory }\end{array}$ & $\begin{array}{l}\text { Inventory / independent } \\
\text { demand }\end{array}$ & - \\
\hline & & Hendry et al. (1996) & One-dimensional & $\begin{array}{l}\text { several types (diameters) } \\
\text { inventory (limited) }\end{array}$ & Inventory & - \\
\hline & & Leão and Toledo (2016) & One-dimensional & $\begin{array}{l}\text { Several types (grades) / } \\
\text { inventory }\end{array}$ & Inventory & - \\
\hline & & Malik et al. (2009) & One-dimensional & $\begin{array}{l}\text { Several types (grades) / } \\
\text { no inventory }\end{array}$ & Inventory & - \\
\hline & & $\begin{array}{l}\text { Poldi and de Araujo } \\
\text { (2016) }\end{array}$ & One-dimensional & $\begin{array}{l}\text { Several types (lengths) } \\
\text { inventory / object } \\
\text { availability }\end{array}$ & Inventory & - \\
\hline & & $\begin{array}{l}\text { Poltroniere et al. (2016, } \\
\text { 2008) }\end{array}$ & One-dimensional & $\begin{array}{l}\text { Several types (grades) / } \\
\text { inventory }\end{array}$ & Inventory & - \\
\hline & & Reinders (1992) & One/two-dimensional & $\begin{array}{l}\text { Several types (classes) / } \\
\text { inventory }\end{array}$ & $\begin{array}{l}\text { Independent demand / } \\
\text { inventory }\end{array}$ & \\
\hline & & & & objects availability & $\begin{array}{l}\text { Out of stock / purchase } \\
\text { (limited) }\end{array}$ & - \\
\hline & & Silva et al. (2014) & Two-dimensional & $\begin{array}{l}\text { One type / inventory / } \\
\text { leftover }\end{array}$ & Inventory & - \\
\hline & & $\begin{array}{l}\text { Trkman and Gradisar } \\
\text { (2007) }\end{array}$ & One-dimensional & $\begin{array}{l}\text { Several types (lengths) / } \\
\text { leftover } \\
\text { several types (length, } \\
\text { width and depth) }\end{array}$ & $\begin{array}{l}\text { No inventory / one order } \\
\text { per period }\end{array}$ & - \\
\hline & & Viegas et al. (2016) & Three-dimensional & $\begin{array}{l}\text { Inventory / object } \\
\text { availability } \\
\text { objects obtained from } \\
\text { suppliers }\end{array}$ & Inventory & - \\
\hline & \multirow[t]{9}{*}{$\begin{array}{l}\text { Levels } 2 \text { and } 3 \\
-/ \text { L2/L3/M }\end{array}$} & $\begin{array}{l}\text { Alem and Morabito } \\
\text { (2012) }\end{array}$ & Two-dimensional & One type & No inventory & $\begin{array}{l}\text { Stochastic demand / } \\
\text { backlog } \\
\text { inventory (limited) }\end{array}$ \\
\hline & & $\begin{array}{l}\text { Alem and Morabito } \\
\text { (2013) }\end{array}$ & Two-dimensional & One type & No inventory & $\begin{array}{l}\text { Stochastic demand / } \\
\text { backlog } \\
\text { inventory }\end{array}$ \\
\hline & & Ghidini et al. (2007) & Two-dimensional & Several types (thickness) & No inventory & Inventory \\
\hline & & Gramani et al. (2009) & Two-dimensional & One type & No inventory & Inventory \\
\hline & & Gramani et al. (2011) & Two-dimensional & One type & Inventory & Inventory \\
\hline & & Santos et al. (2011) & Two-dimensional & Several types (thickness) & Inventory (limited) & $\begin{array}{l}\text { Inventory / safety } \\
\text { inventory }\end{array}$ \\
\hline & & Suliman (2012) & One-dimensional & $\begin{array}{l}\text { One type / inventory cost } \\
\text { object availability }\end{array}$ & Inventory / purchase cost & Inventory / backlog cost \\
\hline & & Vanzela et al. (2017) & Two-dimensional & Several types (thickness) & Inventory & $\begin{array}{l}\text { Inventory / safety } \\
\text { inventory }\end{array}$ \\
\hline & & Wu et al. (2017) & One-dimensional & One type & No inventory & Inventory \\
\hline & \multirow[t]{4}{*}{$\begin{array}{l}\text { Levels } 1,2 \text { and } 3 \\
\text { L1/L2/L3/M }\end{array}$} & $\begin{array}{l}\text { Arbib and Marinelli } \\
(2005)\end{array}$ & One-dimensional & One type / inventory & Inventory (limited) & No inventory \\
\hline & & Melega et al. (2016) & One-dimensional & $\begin{array}{l}\text { Several types (lengths) } \\
\text { inventory / object } \\
\text { availability }\end{array}$ & No inventory & $\begin{array}{l}\text { Inventory } \\
\text { directly pieces }\end{array}$ \\
\hline & & Ouhimmou et al. (2008) & Two-dimensional & $\begin{array}{l}\text { several types (qualities) } \\
\text { Inventory / } \\
\text { transportation } \\
\text { supplier capacity }\end{array}$ & $\begin{array}{l}\text { Inventory / } \\
\text { transportation }\end{array}$ & $\begin{array}{l}\text { Inventory / purchase } \\
\text { transportation } \\
\text { directly pieces }\end{array}$ \\
\hline & & & & $\begin{array}{l}\text { several types (materials, } \\
\text { colors) }\end{array}$ & $\begin{array}{l}\text { Upper and lower bound } \\
\text { demand }\end{array}$ & \\
\hline \multirow[t]{2}{*}{$\begin{array}{l}\text { Multi-level and } \\
\text { single-period }\end{array}$} & $\begin{array}{l}\text { Levels } 1 \text { and } 2 \\
\text { L1/L2/-/S }\end{array}$ & Silva et al. (2015) & Two-dimensional & $\begin{array}{l}\text { Minimum production } \\
\text { limited use from stock }\end{array}$ & $\begin{array}{l}\text { Minimum cutting pattern } \\
\text { length }\end{array}$ & - \\
\hline & $\begin{array}{l}\text { Levels } 2 \text { and } 3 \\
\text { /L2/L3/S }\end{array}$ & Farley (1988) & Two-dimensional & $\begin{array}{l}\text { Several types } \\
\text { (materials,colors) }\end{array}$ & $\begin{array}{l}\text { Oversupply / } \\
\text { undersupply }\end{array}$ & Directly pieces \\
\hline \multirow[t]{4}{*}{$\begin{array}{l}\text { Single-level and } \\
\text { multi-period }\end{array}$} & \multirow[t]{4}{*}{$\begin{array}{l}\text { Level } 2 \\
-/ \text { L2/-/M }\end{array}$} & $\begin{array}{l}\text { Aktin and Özdemir } \\
\text { (2009) }\end{array}$ & One-dimensional & $\begin{array}{l}\text { One type / object } \\
\text { availability }\end{array}$ & No inventory & - \\
\hline & & $\begin{array}{l}\text { Gramani and França } \\
\text { (2006) }\end{array}$ & Two-dimensional & One type & Inventory & - \\
\hline & & Prata et al. (2015) & One-dimensional & Several types (lengths) & No inventory & - \\
\hline & & $\begin{array}{l}\text { Respício and Captivo } \\
(2002)\end{array}$ & One-dimensional & Several types (families) & $\begin{array}{l}\text { Initial inventory / } \\
\text { cumulative demand }\end{array}$ & - \\
\hline
\end{tabular}


Table 5

Detailed capacity-related features.

\begin{tabular}{|c|c|c|c|c|c|c|c|}
\hline \multirow{2}{*}{$\begin{array}{l}\text { Types of } \\
\text { integration }\end{array}$} & \multirow{2}{*}{$\begin{array}{l}\text { Levels of } \\
\text { integration }\end{array}$} & \multirow[b]{2}{*}{ Papers } & \multicolumn{3}{|c|}{ Capacity levels } & \multirow[b]{2}{*}{ Capacity } & \multirow[b]{2}{*}{ Setup } \\
\hline & & & Level 1 & Level 2 & Level 3 & & \\
\hline \multirow{24}{*}{$\begin{array}{l}\text { Multi-level } \\
\text { and } \\
\text { multi-period }\end{array}$} & \multirow{12}{*}{$\begin{array}{l}\text { Levels } 1 \text { and } 2 \\
\text { L1/L2/-/M }\end{array}$} & Agostinho et al. (2016) & - & - & - & - & - \\
\hline & & Campello et al. (2017) & $\checkmark$ & - & - & $\begin{array}{l}\text { Total amount of material (ton) } \\
\text { (several machines) }\end{array}$ & $\begin{array}{l}\text { Setup cost / setup in capacity } \\
\text { (object) }\end{array}$ \\
\hline & & Correia et al. (2004) & - & - & - & - & - \\
\hline & & Hendry et al. (1996) & $\checkmark$ & - & - & Total time & $\begin{array}{l}\text { Setup constraint (object) } \\
\text { setup time (object) }\end{array}$ \\
\hline & & Leão and Toledo (2016) & - & $\checkmark$ & - & Total time (several machines) & Setup cost / time (object) \\
\hline & & Malik et al. (2009) & $\checkmark$ & - & - & Total time & Setup cost / time (object) \\
\hline & & Poldi and de Araujo (2016) & - & - & - & - & - \\
\hline & & Poltroniere et al. (2016, 2008) & $\checkmark$ & - & - & $\begin{array}{l}\text { Total amount of material (ton) } \\
\text { (several machines) }\end{array}$ & $\begin{array}{l}\text { Setup cost / setup in capacity } \\
\text { (object) }\end{array}$ \\
\hline & & Reinders (1992) & - & $\checkmark$ & - & Total time with over time & - \\
\hline & & Silva et al. (2014) & - & - & - & - & - \\
\hline & & Trkman and Gradisar (2007) & - & - & - & - & - \\
\hline & & Viegas et al. (2016) & - & - & - & - & - \\
\hline & \multirow{9}{*}{$\begin{array}{l}\text { Levels } 2 \text { and } 3 \\
-/ \mathrm{L} 2 / \mathrm{L} 3 / \mathrm{M}\end{array}$} & Alem and Morabito (2012) & - & - & $\checkmark$ & Total time with overtime (limited) & Setup cost (final product) \\
\hline & & Alem and Morabito (2013) & - & $\checkmark$ & $\checkmark$ & Total time with overtime (limited) & $\begin{array}{l}\text { Stochastic setup time (pattern) } \\
\text { setup constraint (pattern) }\end{array}$ \\
\hline & & Ghidini et al. (2007) & - & $\checkmark$ & $\checkmark$ & Total time & Setup cost (pattern) \\
\hline & & Gramani et al. (2009) & - & $\checkmark$ & - & Total area of cut material & Setup cost (final product) \\
\hline & & Gramani et al. (2011) & - & $\checkmark$ & - & Total time & - \\
\hline & & Santos et al. (2011) & - & $\checkmark$ & $\checkmark$ & Saw cycle / total time (several machines) & Setup cost / time (pattern) \\
\hline & & Suliman (2012) & - & $\checkmark$ & - & Total number of cuts & Setup cost (pattern) \\
\hline & & Vanzela et al. (2017) & - & $\checkmark$ & - & Saw cycles & - \\
\hline & & Wu et al. (2017) & - & - & $\checkmark$ & Total time & Setup cost / time (final product) \\
\hline & \multirow{3}{*}{$\begin{array}{l}\text { Levels } 1,2 \text { and } 3 \\
\text { L1/L2/L3/M }\end{array}$} & Arbib and Marinelli (2005) & - & $\checkmark$ & - & Total of cut material & Setup cost (object delivery) \\
\hline & & Melega et al. (2016) & - & - & $\checkmark$ & Total time & Setup cost / time (final product) \\
\hline & & Ouhimmou et al. (2008) & - & $\checkmark$ & $\checkmark$ & $\begin{array}{l}\text { Total time / total amount (volume) } \\
\text { (several plants) }\end{array}$ & $\begin{array}{l}\text { Setup cost / time (cutting machine) } \\
\text { setup cost (machine) }\end{array}$ \\
\hline \multirow[t]{2}{*}{$\begin{array}{l}\text { Multi-level and } \\
\text { single-period }\end{array}$} & $\begin{array}{l}\text { Levels } 1 \text { and } 2 \\
\text { L1/L2/-/S }\end{array}$ & Silva et al. (2015) & - & - & - & - & Setup constraint (object/pattern) \\
\hline & $\begin{array}{l}\text { Levels } 2 \text { and } 3 \\
-/ \mathrm{L} 2 / \mathrm{L} 3 / \mathrm{S}\end{array}$ & Farley (1988) & - & $\checkmark$ & $\checkmark$ & $\begin{array}{l}\text { Total length and height of cut material } \\
\text { total time (several machines) }\end{array}$ & Setup cost (cut of object) \\
\hline \multirow{4}{*}{$\begin{array}{l}\text { Single-level } \\
\text { and } \\
\text { multi-period }\end{array}$} & \multirow[t]{4}{*}{$\begin{array}{l}\text { Level } 2 \\
-/ \mathrm{L} 2 /-/ \mathrm{M}\end{array}$} & Aktin and Özdemir (2009) & - & $\checkmark$ & - & $\begin{array}{l}\text { Total time with overtime and } \\
\text { excess of overtime }\end{array}$ & Setup cost / time (pattern) \\
\hline & & Gramani and França (2006) & - & $\checkmark$ & - & Total time & Setup cost (use of cutting machine) \\
\hline & & Prata et al. (2015) & - & - & - & - & - \\
\hline & & Respício and Captivo (2002) & - & $\checkmark$ & - & Total processing time & - \\
\hline
\end{tabular}

production levels (level 1, level 2 or level 3 ) are being considered in the problem. In some cases, two sub-levels are considered for the cutting stock problem (level 2) meaning that two cutting operations are done, one after the other. This is indicated by adding the number of sub-levels between brackets. With respect to the integration across time periods, we indicate if the paper considers a single or multiple time periods, and we also indicate with a "*” the papers that consider sub-periods, i.e., a time period is split into sub-periods according to some characteristic, such as cutting machine capacity. Finally, we indicate if the problem originates from an application in a specific industry. All the papers included in Table 3 consider a finite planning horizon and discrete time periods. As said before, the three papers that consider an infinite planning horizon in a continuous time model are described separately.

From Table 3, the variety in the different degrees of integration is immediately clear. Some papers extend the standard cutting stock problem to deal with multiple time periods, while others keep the assumption of a single time period but extend the problem to multiple production levels. Most of the papers deal with an integration of both types, but this is usually restricted to two levels, i.e., either level 1 and level 2 are integrated or level 2 and level 3 are integrated. Only a limited number of papers deal with multiple time periods and an integration between the three production levels. We will now analyze each case separately.

\subsubsection{Integration across multiple periods and levels 1 and 2}

(L1/L2/-/M)

Analyzing Table 3 in more detail, we see that most of the studies propose models that treat both types of integration, i.e., among different time-periods and among different levels. Firstly, we will start with papers that consider the integration between level 1 and level 2, i.e., the models have decision variables related to the production (inventory, purchase or setup) and cutting of objects over a planning horizon. The integration between these two levels appears in different applications found in the metal, furniture and, mainly, the paper industry. Some papers (Agostinho, Cherri, de Araujo, \& Nascimento, 2016; Correia, Oliveira, \& Ferreira, 2004; Poldi \& de Araujo, 2016; Reinders, 1992; Silva, Alvelos, \& Valério de Carvalho, 2014; Trkman \& Gradisar, 2007; Viegas, Vieira, Henriques, \& Sousa, 2016) assume that the production level of objects is already decided, as a parameter, and the inventory balance constraints at level 1 just model the planning of objects in stock. In cases where leftovers are allowed, either they are added to the stock for the next days, i.e., the usable leftovers of one day are considered as new stock objects in the following days (Trkman \& Gradisar, 2007; Viegas et al., 2016) or the inventory balance constraint for the leftovers is modeled (Agostinho et al., 2016; Silva et al., 2014). These models do not take into account a setup for producing objects. Consequently, there are also no setup costs associated with production at level 1 and no capacity constraint at level 1 is modeled. In our generalized 3-level model, this implies that level 1 is modeled just using constraint (25) via 
an appropriate setting of the $X_{t}^{o}$ variables, which in this case are considered as a parameter. On the other hand, Hendry, Fok, and Shek (1996), Leão and Toledo (2016), Poltroniere, de Araujo, and Poldi (2016), Poltroniere, Poldi, Toledo, and Arenales (2008) and Campello, Oliveira, Ayres, and Ghidini (2017) proposed integrated models where at level 1 a complete capacitated lot-sizing problem with setup is modeled.

In Malik, Qiu, and Taplin (2009), the number of pieces cut from an object according to a cutting pattern is a decision variable, whereas the number of objects cut according to a cutting pattern is an input parameter. A constraint guarantees that the number of objects produced over the whole planning horizon is equal to the number of objects cut in the cutting process and there is no inventory of objects. A capacity constraint limits the number of objects produced in each period at level 1 . In all these papers, a multi-period cutting stock problem at level 2 is modeled, in which cut pieces can be kept in inventory using an inventory balance constraint. In addition, Reinders (1992) models a capacity constraint in the cutting stock problem and overtime can be used, i.e., if necessary, additional time is available to the cutting process. This results in adding an overtime variable in constraints (24) of the G3ILSCS model, and penalizing this variable in the objective function. It is worth mentioning that Reinders (1992) and Correia et al. (2004) proposed linear programming models composed of three production processes. The first production process corresponds to level 1 of the classification and the second and third production processes correspond to level 2 of the classification, i.e., the cutting process is performed twice and consecutively. For example, in Reinders (1992) the production planning of tree trunks is done at level 1 , followed by a crosscutting process to produce the logs and a sawing process to produce the boards, which constitute the final demand in the production planning. The crosscutting process and the sawing process correspond to cutting processes belonging to level 2 of the classification and are operated sequentially.

Correia et al. (2004) and Viegas et al. (2016) do not present a mathematical model of the process described, but only discuss the general ideas of the constraints and objective function. In Agostinho et al. (2016), Poldi and de Araujo (2016) and Viegas et al. (2016), the described models are denominated as a multi-period cutting stock problem. However according to this classification, the models are considered as an integrated lot-sizing and cutting stock problem, due to the fact that there are decision variables related to both the inventory and the cutting of the objects at levels 1 and 2 respectively. Campello et al. (2017) present a formulation which is quite similar to the one proposed by Poltroniere et al. (2008) and the authors consider a multi-objective optimization approach to analyze the trade-offs between the LSP and CSP by analyzing the costs variations of these problems simultaneously.

Trkman and Gradisar (2007) proposed a model which consists of satisfying orders set in consecutive time periods, with usable leftovers. Constraints guarantee that the leftovers return to the warehouse and are available for cutting in future time periods, either if they are longer than the size limit or if the costs of returning the stock length to the warehouse are cheaper than the trim loss costs. For each period, a constraint ensures that a new order must be satisfied without backorder or inventory, by either using new objects available in that time period or by objects/leftovers from stock. The authors use a formulation for the cutting stock subproblem based on the model of Kantorovich (1960).

\subsubsection{Integration across multiple periods and levels 2 and 3 \\ $(-/ \mathrm{L} 2 / \mathrm{L} 3 / \mathrm{M})$}

Considering papers that address integrated problems at level 2 and level 3, the main models are based on applications in the furniture industry, with the exceptions of Suliman (2012) which discusses an application in the aluminum industry and Wu, Akar- tunali, Jans, and Liang (2017) which analyze a model for a general application. The papers differ from each other mainly at level 3, where in some cases (Gramani, França, \& Arenales, 2011; Suliman, 2012; Vanzela et al., 2017), the production planning of the final products takes place using only the demand balance constraint of final products. In our generalized 3-level model, this implies that level 3 is modeled just using constraint (18). In others studies, there is the addition of a capacity constraint (Alem \& Morabito, 2013; Ghidini, Alem, \& Arenales, 2007; Santos, de Araujo, \& Rangel, 2011) and a setup cost (Alem \& Morabito, 2012; Gramani et al., 2009). In Wu et al. (2017), a capacitated lot-sizing problem with setup cost and setup time is modeled at level 3 , in which the formulation proposed is based on the one presented in Gramani et al. (2009). In these models, the capacity constraint at level 3 represents the capacity of the production process necessary to obtain the final products, such as drilling or assembly.

In some papers, there are further restrictions with respect to the inventory accumulation. A number of studies (Alem \& Morabito, 2012,2013; Ghidini et al., 2007; Gramani et al., 2009; Wu et al., 2017) impose that inventory accumulation is allowed at the level of the final products (level 3), but not at the level of the cut pieces (level 2). In our generalized model, this would imply that the $S_{t}^{p}$ variables are set to zero in constraint (21). Consequently, if a piece is used in the production process at level 3, it must be cut at level 2 in the same time period. In some studies (Gramani et al., 2009,2011; Vanzela et al., 2017), a capacity constraint is modeled at level 2, while in others (Alem \& Morabito, 2013; Ghidini et al., 2007; Suliman, 2012) there is also the addition of a setup cost or setup time. Only in Santos et al. (2011) a multi-period capacitated cutting stock problem with setup cost and setup time takes place at level 2. In several models, additional constraints and variables are needed to model the specifics of the production process. For example in the furniture industry (Alem \& Morabito, 2012,2013; Santos et al., 2011; Vanzela et al., 2017), safety stock, overtime or limitations with respect to the saw cycle on the cutting machines need to be taken into account in order to obtain a practical feasible solution.

\subsubsection{Integration across multiple periods and levels 1, 2 and 3 (L1/L2/L3/M)}

Only a few papers in the literature address the integration between the three production levels. These models typically represent simplifications when compared to the G3ILSCS model proposed in this paper, since they do not include all the features present in the generalized 3-level integrated model. Arbib and Marinelli (2005) present a case study that arises in the production of gear belts. At level 1, a lot-sizing model considers the trade-off between objects inventory and objects delivery to the cutting process. The quantity of objects that must be provided to the cutting process cannot be less than what is needed and, once sent to the cutting process, a setup cost associated with the delivery of material is imposed. Level 2 consists basically of a multi-period cutting stock problem with a capacity constraint. The cut pieces can either be transformed directly into a final product, or they can be assembled with other pieces to form a final product. The stock of pieces is limited by an inventory capacity, which amounts to imposing an upper bound on the $S_{t}^{p}$ variables in the generalized model. At level 3, the production planning ensures that the demand of each final product is satisfied in each period directly from production, without inventory, which is equivalent to setting the $S_{t}^{f}$ variables to zero in constraint (18) of our generalized model.

Ouhimmou, D’Amours, Beauregard, Ait-Kadi, and Singh Chauhan (2008) study the processes of a furniture company. The whole system observed in the company, which consists of the activities of sawing, drying in a kiln and transportation, is not fully modeled by the authors in the presented model. At level 1, the planning of 
the procurement of objects takes place, with a supplier capacity constraint and a flow balancing constraint at each sawmill. Level 2 consists of a capacitated multi-period cutting stock problem with a setup for each object processed at the sawmill. The final process is the drying process and is modeled using the lot-sizing problem. The drying process involves transforming green wood boards (pieces) into dry wood boards (final products). Each piece passes through the drying process and subsequently becomes a final product. Constraints ensure that the capacity in the kiln is not violated by the production of pieces and a setup is necessary for each piece in the drying process. The demand of customers needs to be met either from production or from purchase on the market.

In Melega, de Araujo, and Jans (2016), several models with a general application that integrate the lot-sizing problem and cutting stock problem at different levels are proposed. One of the models is composed of three levels, where at level 1 , a demand balance constraint of objects is modeled with a parameter that limits the number of objects available in each period for each type of object, i.e., the production of objects is assumed as given and the decisions are only related to the planning of the objects in stock. At level 2, a multi-period cutting stock problem takes place, where a constraint ensures that a sufficient amount of pieces is cut to meet the planned production. Cut pieces cannot be kept in inventory and must be processed at level 3 in the same time period. Each piece at level 2 corresponds directly to a final product at level 3 and this level is modeled by a capacitated lot-sizing problem with setup.

\subsubsection{Integration across multiple levels in a single period (L1/L2/-/S and $-/ \mathrm{L} 2 / \mathrm{L} 3 / \mathrm{S})$}

Two studies (Farley, 1988; Silva et al., 2015) address integrated models which take into account just a single time period. The models deal only with the integration between levels. Farley (1988) proposed a model to describe the production process in the textile industry. According to the classification, the model integrates level 2 and level 3 , in which at level 3 constraints guarantee a minimum and maximum production level in the sewing lines, which consists of the processes performed after the cutting and at level 2 a capacitated cutting stock problem with setup cost is modeled. In the model, each cut piece at the level 2 corresponds directly to a final product at level 3, i.e., there is no assembly process of pieces into final products. In our generalized 3-level model, this implies that there is a one-to-one relationship between the cut pieces and final products, which can be modeled via an appropriate setting of the $r_{f}^{p}$ parameter. One of the costs in the objective function is associated with oversupply quantity, which according to the authors represents the idea of holding cost in some form. Also dealing with the production process in a textile industry, Silva et al. (2015) propose a model which integrates level 1 and level 2. At level 1, the production planning of objects is done considering a minimum production quantity, a setup constraint for each type of produced object and a maximum quantity of objects that can be used from inventory, guaranteeing a sufficient amount of objects necessary in the cutting process. At level 2, a cutting stock problem with a setup constraint for each cutting pattern is modeled, considering an upper and a lower bound demand for each piece and additional constraints which ensure minimum length for each cutting pattern.

\subsubsection{Integration across multiple time periods at a single level $(-/ \mathrm{L} 2 /-/ \mathrm{M})$}

Four studies propose models which consider the integration only across multiple periods at level 2 . There is no integration between production levels and the cutting stock problem is extended to multiple periods. These models basically consider simplifications of the constraints (21)-(24) and (29) of the G3ILSCS model. Respício and Captivo (2002) proposed a model which is an extension of the formulation presented in Gilmore and Gomory (1961) by considering cumulative demand and initial inventory to treat with the absence of capacity to meet the pieces demand. Some aspects are neglected such as holding costs over the whole planning horizon. A capacity constraint is modeled in terms of the total processing time of objects in each period. In Gramani and França (2006), a problem from the furniture industry is modeled, in which the demand of final products is converted into demand of pieces and the resulting model is a capacitated multi-period cutting stock problem with setup costs. In their model, the setup is related to the overall production level in a specific period, i.e., if there is some production in a period, a setup must be done in that period, otherwise no setup is necessary.

In Aktin and Özdemir (2009), a two-stage methodology is developed and implemented at a medical apparatus manufacturer. In the first stage, a model is used to generate the cutting patterns with minimum waste, necessary to meet the demand of pieces. These generated cutting patterns are used as input parameters in the second stage, which consists of a capacitated cutting stock problem with setup costs and setup time for each cutting pattern. The whole process is considered for each order and a due date is determined considering the minimum number of days required to fulfill the demand of this order, which is a negotiation between the manufacturer and the customer. The total time used to cut the objects and to setup the machine for each cutting pattern cannot exceed the total time available (regular time, over time and excess-of-overtime). A constraint guarantees that the number of objects used in the cutting process cannot exceed the available quantity. In our generalized integrated model, this condition is modeled considering an upper bound to the $Z_{j t}^{0}$ variable.

Prata, Pitombeira-Neto, and de Moraes Sales (2015) proposed a model for the problem found in the precast concrete beams industry. The authors notice that the problem studied is similar to the multi-period cutting stock problem, where the forms used to model the concrete beams represent the objects and the beams represent the pieces which are demanded by the customers. The waste in the problem is considered as loss of production, which is due to unfilled spaces in the forms (objects). In the model, the number of time periods necessary to meet the demand of pieces (precast beams) is determined by dividing the total demand by the total capacity of the forms in each day. The multiple time periods are basically used in order to reduce the loss and avoid carrying inventory, in this way, the inventory of pieces is not modeled. The formulation of the cutting stock problem is based on the model proposed by Kantorovich (1960).

These models do not have an integration between the levels and the integration takes place across periods taking into account the production planning for several periods at the level of the cutting stock problem and are classified as multi-period cutting stock problems.

\subsubsection{Continuous time periods}

Three papers (Krichagina, Rubio, Taksar, \& Wein, 1998; Nonås \& Thorstenson, 2000,2008) differ from the others due to the type of time horizon used in the model. These three papers consider an infinite planning horizon and a continuous time scale. Although the models presented in these papers do not entirely fit in the proposed framework, their classification contributes to a more general review of the literature. In Krichagina et al. (1998), besides dealing with continuous time periods, the model also takes into account two levels of integration. The constraints at level 1 deal with idle processing time in the paper machine, i.e., the decision to turn the paper machine on and off in order to produce the objects, whereas the constraints at level 2 guarantee that the demand of pieces is met allowing backorder. On the other hand, 
Nonås and Thorstenson $(2000,2008)$ propose a model for just one level (level 2), which models the cutting stock problem using cycle times. It is worth mentioning that the authors classify the model as an integrated lot-sizing and cutting stock problem. However, according to this classification, the model is considered as a cutting stock problem with an integration across time periods, due to the fact that there are no constraints and variables related to the production of objects and final products.

\subsection{Discussion of further operational aspects}

In this section, we discuss some further particularities of the various models proposed in the literature. Table 4 presents features related to the objects (fifth column). These features are present in the papers that model the lot-sizing problem at level 1 , but also in the other papers that do not consider any decision variable related to level 1 , since these features also have an impact on the cutting process. With respect to the cutting stock problem at level 2, we indicate the dimensionality of the problem and features regarding the pieces (fourth and sixth column, respectively). In the last column we report the features with respect to the final products in the lot-sizing problem at level 3. The discussions of further operational aspects in Table 4 are mainly focused on the inventory balance constraints considering the three levels of production (constraints (18), (21) and (25) of our G3ILSCS model).

\subsubsection{Additional aspects regarding the objects}

Analyzing the features of the objects, we can see from Table 4 that less than half of the studies consider only one type of object, whereas most of the studies address multiple types, which correspond to different materials, lengths, colors, classes, diameters, families, grades, thicknesses or qualities. In some studies, the objects can be available in a limited number (Agostinho et al., 2016; Aktin \& Özdemir, 2009; Melega et al., 2016; Poldi \& de Araujo, 2016; Reinders, 1992; Suliman, 2012; Viegas et al., 2016). In other studies that consider usable leftover, there are also residual objects available, in addition to the limited number of standard objects (Agostinho et al., 2016; Silva et al., 2014; Trkman \& Gradisar, 2007; Viegas et al., 2016). In most of the papers that consider level 1, i.e., there is a decision variable related to this level, the inventory of objects is taken into account in the demand balance constraint. In some studies (Hendry et al., 1996; Silva et al., 2015) the number of objects that can be stocked or used from stock is limited, while in other studies (Correia et al., 2004; Krichagina et al., 1998; Malik et al., 2009) no inventory of objects is allowed at level 1.

Ouhimmou et al. (2008) consider additional constraints related to the transportation of the objects to the cutting process, and related to the suppliers' capacity with respect to the acquisition of the objects. In Silva et al. (2015) a minimum production quantity is imposed if there is any production of objects. Suliman (2012) does not model a demand balance constraint of objects. However, a holding cost is related to the difference between the number of objects used in the cutting process and the number of objects available in each period (parameter). In Poldi and de Araujo (2016), the number of objects acquired in each period is considered as a parameter in a first model and also as an additional decision variable in a second model, in order to enable a more realistic decision. Viegas et al. (2016) also consider a variable, in the demand balance constraints of objects, which is related to the number of objects obtained from the suppliers. As discussed before, in some of the papers that include level 1 (Agostinho et al., 2016; Melega et al., 2016; Poldi \& de Araujo, 2016; Reinders, 1992; Viegas et al., 2016), it is assumed that the production of objects is already decided up front. As such, the demand balance constraints only relate to the planning of objects in stock.
3.3.2. Additional aspects regarding the dimensionality and pieces in the cutting stock problem (Level 2)

Table 4 indicates that the cutting problems at level 2 deal with either one, two and three dimensions, and the latter appears less frequently. Only one of the studies addressed in this literature review considered a three-dimensional cutting stock problem (Viegas et al., 2016). In general, the dimensionality depends on the type of the applications. For instance, there are many papers that present applications in the furniture industry, where the two-dimensional case appears. In some applications, where the cutting stock problem arises at two sub-levels (Correia et al., 2004; Reinders, 1992), the cutting process changes in dimensionality from one sub-level to the other sub-level. In Wu et al. (2017), although a two-dimensional cutting process arises, one of the piece dimensions (width) is considered fixed. In this way, we classified this as a one-dimensional cutting process.

For most of the studies in the literature, the demand balance constraint of pieces is modeled at level 2. The inventory of pieces is modeled either by oversupply (Farley, 1988), initial inventory (Respício \& Captivo, 2002) or inventory variables (Agostinho et al., 2016; Arbib \& Marinelli, 2005; Campello et al., 2017; Correia et al., 2004; Gramani \& França, 2006; Gramani et al., 2011; Hendry et al., 1996; Krichagina et al., 1998; Leão \& Toledo, 2016; Malik et al., 2009; Ouhimmou et al., 2008; Poltroniere et al., 2016; Poltroniere et al., 2008; Reinders, 1992; Santos et al., 2011; Silva et al., 2014; Suliman, 2012; Vanzela et al., 2017). Due to the specific environment which is present, some practical applications need additional constraints to model the inventory limits (Arbib \& Marinelli, 2005; Santos et al., 2011), upper and lower bound demand of pieces (Silva et al., 2015), cumulative demand (Respício \& Captivo, 2002) or the transportation of the pieces (Ouhimmou et al., 2008). In order to meet the pieces demand, some studies consider the possibility of externally purchasing the pieces in the demand balance constraints with an additional cost in the objective function (Reinders, 1992). Other strategies, such as undersupply (Farley, 1988), out of stock (Reinders, 1992), or backorders (Krichagina et al., 1998) are also considered in the models to meet the pieces demand. Only a few papers consider independent demand of pieces at level 2 (Correia et al., 2004; Reinders, 1992). In the studies where the inventory of pieces is not incorporated at level 2 (Aktin \& Özdemir, 2009; Alem \& Morabito, 2012,2013; Ghidini et al., 2007; Gramani et al., 2009; Melega et al., 2016; Prata et al., 2015; Trkman \& Gradisar, 2007; Wu et al., 2017), a piece necessary in the assembly or further processing must be cut in the same time period as the production of the corresponding final product.

\subsubsection{Additional aspects regarding the final products}

As mentioned before, in some applications (textile, wood processing furniture), there is a one-to-one relationship between a cut piece and a final product. After being cut, the pieces undergo some transformation process to become final products, but there is no assembly process (Farley, 1988; Melega et al., 2016; Ouhimmou et al., 2008). However, most of the papers that model level 3 consider an assembly structure, in which cut pieces correspond to components which are assembled into a final product. In general, the demand balance constraints at level 3 contain only the decisions related to the production and stocking of final products (Alem \& Morabito, 2012,2013; Ghidini et al., 2007; Gramani et al., 2009,2011; Melega et al., 2016; Ouhimmou et al., 2008; Santos et al., 2011; Suliman, 2012; Vanzela et al., 2017; Wu et al., 2017). In a few other papers (Alem \& Morabito, 2012,2013; Ouhimmou et al., 2008), purchase and backlog variables are added in the balance constraints in order to meet the demand of final products. In Suliman (2012), there is a cost in the objective function related to the non-fulfilled demand of final products. Similar to the extensions at level 1 and level 2, safety inventory and inventory limits 
can be added at level 3 (Alem \& Morabito, 2012; Santos et al., 2011; Vanzela et al., 2017). The complexity at level 3 is increased if a stochastic environment (with respect to demand and production costs) is taken into account (Alem \& Morabito, 2012,2013).

\subsubsection{Additional aspects regarding capacity-related features}

In Table 5, we provide a further analysis in terms of capacity constraints and setups (constraints (19), (20), (23), (24), (26) and (27) of our G3ILSCS model). Concerning the capacity, we indicate the presence or absence of a capacity constraint at each of the three levels and report the features of this capacity in terms of resource consumption. Constraints related specifically to the cutting pattern generation are not considered as capacity constraints in this table. For example, in most of the furniture industries the cutting machines impose that only orthogonal guillotine cuts can be made. A cut is of orthogonal guillotine type if, when applied to a rectangle, it produces two other rectangles. This feature is not considered as a capacity constraint in this paper. With respect to the setup, we evaluate the type of the setup considered (cost and/or time) and the type of product the setup refers to (i.e., a setup related to the object, cutting machine, cutting pattern or final product).

We observe that capacity constraints are most frequently imposed at level 2, followed by level 3 and then by level 1 . In the studies which consider more than one level, the capacity constraint is generally imposed at just one level. However, some papers (Alem \& Morabito, 2013; Farley, 1988; Ghidini et al., 2007; Ouhimmou et al., 2008; Santos et al., 2011) consider a capacity constraint at more than one level, mostly in models which integrate level 2 and level 3. None of the papers has a capacity constraint at each of the three levels.

The resource consumption in the capacity constraint is stated mostly in terms of total time available. However, the capacity constraint can be imposed in different ways according to the specific application and the level that it is related to, such as, the total amount of produced material (Campello et al., 2017; Poltroniere et al., 2016; Poltroniere et al., 2008), total amount or area of cut material (Arbib \& Marinelli, 2005; Gramani et al., 2009), total length and height of cut material (Farley, 1988), saw cycles (Santos et al., 2011; Vanzela et al., 2017) and number of cuts (Suliman, 2012). Krichagina et al. (1998) consider a capacity constraint that calculates the idleness of the machine with respect to the production of objects at level 1 and guarantees that it is always positive. In Respício and Captivo (2002), the capacity constraint is modeled in terms of the total processing time of objects cut in each period. In papers where a capacity is considered at more than one level, the resource consumption is not necessarily modeled in the same way at each level (Farley, 1988; Ouhimmou et al., 2008; Santos et al., 2011). In some studies (Aktin \& Özdemir, 2009; Alem \& Morabito, 2012,2013; Reinders, 1992), overtime is allowed, whereas in others (Campello et al., 2017; Farley, 1988; Leão \& Toledo, 2016; Poltroniere et al., 2016; Poltroniere et al., 2008; Santos et al., 2011), several machines are used to produce the items.

It is worth to mention that the addition of setups in a model considerably increases its complexity. Faced with this challenge, some studies consider the occurrence of setups in the model, but only a few of them consider both setup costs and setup times (Aktin \& Özdemir, 2009; Leão \& Toledo, 2016; Malik et al., 2009; Melega et al., 2016; Ouhimmou et al., 2008; Santos et al., 2011; Wu et al., 2017). In some papers, the setup is incorporated in the problem through the consideration of a setup constraint and setup time in capacity constraints, but no setup cost in the objective function is addressed (Alem \& Morabito, 2013; Hendry et al., 1996; Silva et al., 2015). Different classes of setup can be found, such as setups related to the cutting of objects (Farley, 1988), a machine shutdown in objects production (Krichagina et al., 1998), a startup of pieces production (Nonås \& Thorstenson, 2000,2008), the delivery of objects to the cutting process (Arbib \& Marinelli, 2005) and the use of the cutting machine (Gramani \& França, 2006; Ouhimmou et al., 2008). In Poltroniere et al. (2016, 2008) and Campello et al. (2017), each machine on which the objects are produced, has a capacity constraint in terms of tons of objects, which takes into account the quantity of objects produced and the waste of objects due to the changes in the type of object (setup). A stochastic setup time related to the use of a cutting pattern further increases the complexity of the model (Alem \& Morabito, 2013).

\section{Conclusions and new research directions}

In this paper, we are interested in the integration of two well-known problems from the literature, which are the lot-sizing problem and the cutting stock problem. In Section 4.1, we provide conclusions with respect to our proposed generalized model and the classification of the literature, whereas Section 4.2 discusses opportunities for further research.

\subsection{Conclusions with respect to the generalized model and classification}

A generalized 3-level integrated lot-sizing and cutting stock problem (G3ILSCS), which considers two types of integration, is proposed. The G3ILSCS model incorporates several aspects found in practice and enables us to classify the current literature and give directions for future research that addresses integrated problems.

The proposed model is composed of three levels. At the final level (level 3) we have a lot-sizing problem for the production of final products. At the intermediate level (level 2) we have a cutting stock problem based on the idea of cutting patterns and at the first level (level 1), we have a lot-sizing problem related to the production of objects. The proposed classification is based on two aspects: the integration across multiple time periods and the integration between production levels. The integration across time periods comes from the possibility to hold items in inventory. A model that considers more than one time period, i.e., which considers the integration across time periods, but which does not consider more than one level, i.e., only the cutting stock level is included, is classified as a multi-period cutting stock problem. Models that consider the integration between production levels but not across time periods are classified as single-period multi-level production and cutting stock problems. Finally, models that take into account both aspects of integration are classified as integrated lot-sizing and cutting stock problems. Other features are also evaluated, such as the dimensionality in the cutting process, the possibility of holding objects, pieces or final products in stock, and the capacity and setup structure.

In general, the models studied in the literature correspond mainly to simplifications or, in some cases, simple extensions of the generalized 3-level integrated lot-sizing and cutting stock problem (G3ILSCS) presented in this paper. Three papers consider a framework with an infinite time horizon and continuous time scale, which does not fit with the discrete time approach of the G3ILSCS formulation presented here. The classification of the literature shows that most of the studies consider the integration across time periods and the integration between production levels 1 and 2 or between production levels 2 and 3. The large number of papers which integrate level 1 and level 2 is due to the practical applicability of this type of model in the paper industry. On the other hand, the papers that integrate level 2 and level 3 are inspired mainly by applications in the furniture industry. Another relevant feature inherited from the focus on practical applications is the dimensionality of the cutting problem, which is predominantly one-dimensional or two-dimensional. The capacity 
constraint is often employed at just one level and is typically computed in terms of total time consumption. Only a few studies consider both setup cost and setup time in their models. Setups can relate to various aspects such as the cutting of objects, a machine shutdown in the objects production, the startup of the production, the delivery of objects to the cutting process or the use of the cutting machine. Most of the papers consider the possibility of holding pieces in stock. Models that consider level 1 (level 3) most often consider the possibility of holding objects (final products) in stock. At the cutting stock level, however, several papers consider that no cut pieces can be held in inventory. An uncertain environment related to the demand, setup time and production costs is rarely considered in the literature of integrated problems.

After analyzing and classifying the literature of integrated lotsizing and cutting stock problems, we can also conclude that the bulk of the research on this topic has been done fairly recently, i.e., in the past decade. There is still a lot of work to be done on the integrated problems. Some insights and opportunities for future research are discussed next.

\subsection{Further research opportunities}

In the multi-level problems, there might be different characteristics of the production environment that need to be incorporated for each level specifically. In addition, there might be possibilities to integrate the three levels with other decision processes. The opportunities described in this section are derived from the analysis of the tables and will be clustered according to possible extensions related to: 1) the lot-sizing problem at level 1 and level 3;2) the cutting stock problem at level $2 ; 3$ ) extensions that consider other levels of decisions apart from the three levels considered; and 4) other extensions.

Considering the lot-sizing problem, a direct extension which is common in practice and in the lot-sizing literature, is the use of multiple machines to produce the customers' order. This can arise at level 1 and level 3 of the model considering multiple machines used to produce different objects and final products. Further, in practical applications where multi-level lot-sizing problems appear, typically a lead-time offset of one or more periods is required to allow the disaggregation into a feasible machine schedule, or a change in the formulation is needed (Almeder, Klabjan, Traxler, \& Almada-Lobo, 2015). However, none of the papers on the integrated lot-sizing and cutting stock problem consider this issue, which seems to be a good opportunity for future research. Another relevant aspect that can be considered in future research is that in some practical cases, some important components, apart from the cut pieces, might be produced in another (non-cutting) regular manufacturing process. For example, in the tubular furniture industry, an office chair can be composed of a foam seat and backrest that are purchased from the market or produced in another sector of the industry. In the formulation, this would mean that at level 2 , in addition to the constraint for the multi-period cutting stock problem with dependent demand, we would have a lot-sizing problem with dependent demand for the components that are produced in the regular (non-cutting) manufacturing process. In such case, level 2 would consist of several parallel processes: a cutting process to produce the cut pieces and a regular manufacturing process for the other components. As the lot-sizing problems at level 1 and level 3 consider the production of several items, the sequence in which these items are produced can influence the quality, total cost, and even the feasibility of the solution. In such a case, an integrated lot-sizing and scheduling problem with sequence-dependent setups arises at level 1 and level 3 (Copil et al., 2017; Drexl \& Kimms, 1997).

For the cutting stock problem at level 2, multiple machines may also be available, resulting in the problem of assigning orders to parallel or sequential cutting machines (Menon \& Schrage, 2002) or the allocation of cutting patterns to specific machines (Giannelos \& Georgiadis, 2001). Some of the extensions discussed in the literature for the CSP, such as reusable leftovers (Cherri et al., 2014), may be of interest for insertion in the integrated model in order to better describe specific industry practices, for example for industries where the cost for managing the inventory of small pieces are prohibitive, which makes the consideration of reusable leftover in stock attractive. Capacity limitations are important in real life problems and should be taken into account in the models. Henn and Wäscher (2013) notice that in the cutting stock literature (considered up to the end of 2012) no models with setups exist which consider capacity constraints, i.e., there was no model that takes into account the limitations of the capacity in the cutting stage, considering the cutting and the setup processes. Therefore, a multi-period cutting stock problem with a capacity constraint as addressed at level 2 in the G3ILSCS model is not fully explored in the literature to model cutting processes and provides an interesting and relevant avenue for future research. The capacity constraint may not only be related to the production time of the cutting process, but may be related to other aspects, such as saw cycles (Toscano, Rangel, \& Yanasse, 2017; Vanzela et al., 2017). In some industrial applications, delivering the orders on time can be far more important than reducing the resulting waste and the cost of cut objects. Models that consider due dates in the formulation better describe the need of the industry in such a case (Arbib \& Marinelli, 2014; Bennell, Lee, \& Potts, 2013; Braga, Alvez, Macedo, \& de Carvalho, 2015,2016; Li, 1996; Reinertsen \& Vossen, 2010).These papers combine the standard objective of minimizing the number of rolls used with a scheduling term penalizing the tardiness of the cutting operations. This problem is referred to in the literature as the combined Cutting Stock and Scheduling Problem (CSSP). The multi-period setting also appears in these papers, but a shorter planning horizon is considered. In general they assume that it takes exactly one unit of time to cut a stock roll. The consideration of a three dimensional cutting stock problem (Viegas et al., 2016), is also an interesting topic of research that has not been enough explored. The cutting plan described by the current models provides a set of cutting patterns and the corresponding frequencies of the patterns. However, in some settings, it becomes necessary to determine a production plan that also indicates the optimal sequence of the cutting patterns (Wuttke \& Heese, 2018). The inclusion of the pattern sequence in the model may be related to a specific objective function, usually related to a practical application, such as: the minimization of the knives changes, where each insertion and removal of knives takes time to be processed; the minimization of open stacks (i.e. the number of mounting compartments around the cutting machine), in which a stack remains open until the last pattern that contains a piece of the stack is cut; the minimization of the order spread, which refers to the number of open stacks during the cutting process (Foerster \& Wäscher, 1998; Garraffa, Salassa, Vancroonenburg, Vanden Berghe, \& Wauters, 2016; Rinaldi \& Franz, 2007; Yanasse \& Lamosa, 2007).

There are only three papers that consider the three levels, which is itself a good opportunity for future research. In addition to the three levels considered in the G3ILSCS model, there might be possibilities of integration with other decision levels, such as the supplier selection, in which the choice of different suppliers may be based on the quality, price and speed of the orders. The integration with routing and packing/loading of the final products to the customers is also an interesting topic to be explored.

Another important aspect for future research is the consideration of uncertainty. Few papers in the literature of integrated lotsizing and cutting stock problems address optimization problems with uncertain parameters. Alem and Morabito (2012) employed robust optimization tools to derive robust models for production 
planning in the furniture industry, when production costs and product demands are uncertain parameters. Alem and Morabito (2013) proposed a two-stage stochastic optimization model under stochastic demand and setup times. Beraldi, Bruni, and Conforti (2009) consider the case of demand uncertainty for a cutting stock problem. Beyond the various objectives discussed previously for both problems, an alternative approach is a multi-criteria optimization (Wäscher, 1990). In a multi-criteria optimization approach, a good solution is not the result of the optimization of one criterion (such as total cost), but constitutes a good compromise between several criteria. The need for such an alternative approach can arise from the difficulty to obtain real values for the costs in the objective function. Finally, we think that there are opportunities to study the integrated problems in several practical sectors that have not been explored yet. Most of the papers published so far are based on the paper and furniture industry. Any other sector which uses a cutting process and needs some production planning over the time, can be explored.

In conclusion, we see that there is no shortage of challenging and relevant avenues for future research. The resolution of industrial problems will continue to be an important source of inspiration to further refine the models.

\section{Acknowledgments}

This research was funded by the Conselho Nacional de Desenvolvimento Científico e Tecnológico CNPq and Fundação de Amparo a Pesquisa do Estado de São Paulo - FAPESP (process n 2012/206312, 2013/07375-0, 2014/17273-2 and 2016/01860-1).

\section{References}

Agostinho, G. T., Cherri, A. C., de Araujo, S. A., \& Nascimento, D. N. (2016). The multiperiod cutting stock problem with usable leftover. In Annals of Latin-Iberian-American conference on operations research (CLAIO).

Aktin, T., \& Özdemir, R. G. (2009). An integrated approach to the one-dimensional cutting stock problem in coronary stent manufacturing. European Journal of $\mathrm{Op}$ erational Research, 196(2), 737-743.

Alem, D., \& Morabito, R. (2012). Production planning in furniture settings via robust optimization. Computers \& Operations Research, 39(2), 139-150.

Alem, D., \& Morabito, R. (2013). Risk-averse two-stage stochastic programs in furniture plants. OR Spectrum, 35(4), 773-806.

Almeder, C. (2010). A hybrid optimization approach for multi-level capacitated lotsizing problems. European Journal of Operational Research, 200(2), 599-606.

Almeder, C., Klabjan, D., Traxler, R., \& Almada-Lobo, B. (2015). Lead time considerations for the multi-level capacitated lot-sizing problem. European Journal of Operational Research, 241(3), 727-738.

Alves, C., \& Valério de Carvalho, J. M. (2008). A stabilized branch-and-price-and-cut algorithm for the multiple length cutting stock problem. Computers \& Operations Research, 35(4), 1315-1328.

Andrade, R., Birgin, E. G., Morabito, R., \& Ronconi, D. P. (2014). Mip models for two-dimensional non-guillotine cutting problems with usable leftovers. Journal of the Operational Research Society, 65(11), 1649-1663.

de Araujo, S. A., \& Clark, A. (2013). A priori reformulations for joint rolling-horizon scheduling of materials processing and lot-sizing problem. Computers $\mathcal{E}$ Industrial Engineering, 65, 557-585.

de Araujo, S. A., Constantino, A. A., \& Poldi, K. C. (2010). An evolutionary algorithm for the one-dimensional cutting stock problem. International Transactions in $\mathrm{Op}$ erational Research, 18, 115-127.

de Araujo, S. A., Poldi, K. C., \& Smith, J. (2014). A genetic algorithm for the one-dimensional cutting stock problem with setups. Pesquisa Operacional, 34, 165-187.

de Araujo, S. A., de Reyck, B., Degraeve, Z., Fragkos, I., \& Jans, R. (2015). Period decompositions for the capacitated lot sizing problem with setup times. INFORMS Journal on Computing, 27(3), 431-448.

Arbib, C. \& Marinelli, F. (2005). Integrating process optimization and inventory planning in cutting-stock with skiving option: An optimization model and its application. European Journal of Operational Research, 163(3), 617-630.

Arbib, C., \& Marinelli, F. (2014). On cutting stock with due dates. Omega, 46, 11-20.

Arbib, C., Marinelli, F., Rossi, F., \& Iorio, F. D. (2002). Cutting and reuse: An application from automobile component manufacturing. Operations Research, 50(6), 923-934.

Arenales, M., Morabito, R., \& Yanasse, H. (1999). Special issue: Cutting and packing problems. Pesquisa Operacional, 19(2), 107-299.

Arenales, M. N., \& Morabito, R. (1995). An and/or-graph approach to the solution of two-dimensional non-guillotine cutting problems. European Journal of Operational Research, 84(3), 599-617.
Belov, G., \& Scheithauer, G. (2002). A cutting plane algorithm for the one-dimensional cutting stock problem with multiple stock lengths. European Journal of Operational Research, 141(2), 274-294.

Belov, G., \& Scheithauer, G. (2006). A branch-and-cut-and-price algorithm for one-dimensional stock cutting and two-dimensional two-stage cutting. European Journal of Operational Research, 171(1), 85-106.

Bennell, J. A., Lee, L. S., \& Potts, C. N. (2013). A genetic algorithm for two-dimensional bin packing with due dates. International Journal of Production Economics, 145(2), 547-560.

Beraldi, P., Bruni, M. E., \& Conforti, D. (2009). The stochastic trim-loss problem. European Journal of Operational Research, 197, 42-49.

Braga, N., Alvez, C., Macedo, R., \& de Carvalho, J. V. (2015). A model-based heuristic for the combined cutting stock and scheduling problem. Lecture Notes in Computer Science, 9156, 409-505.

Braga, N., Alvez, C., Macedo, R., \& de Carvalho, J. V. (2016). Combined cutting stock and scheduling: a matheuristic approach. International Journal of Innovative Computing and Applications, 17(3), 135-146.

Brahimi, N., Dauzere-Peres, S., Najid, N. M., \& Nordli, A. (2006). Single item lot sizing problems. European Journal of Operational Research, 168(1), 1-16.

Buschkühl, L., Sahling, F., Helber, S., \& Tempelmeier, H. (2010). Dynamic capacitated lot-sizing problems: A classification and review of solution approaches. OR Spectrum, 32(2), 231-261.

Campello, B. S. C., Oliveira, W. A., Ayres, A. O. C., \& Ghidini, C. T. L. S. (2017). Lotsizing problem integrated into cutting stock problem in a paper industry: A multiobjective approach. Cornell University Library. 1703.03024v1 [math.OC].

Cherri, A. C., Arenales, M. N., Yanasse, H. H., Poldi, K. C., \& Vianna, A. C. G. (2014). The one-dimensional cutting stock problem with usable leftovers - a survey. European Journal of Operational Research, 236(2), 395-402.

Christofides, N., \& Whitlock, C. (1977). An algorithm for two-dimensional cutting problems. Operations Research, 25(1), 30-44.

Copil, K., Wörbelauer, M., Meyr, H., \& Tempelmeier, H. (2017). Simultaneous lotsizing and scheduling problems: A classification and review of models. OR Spectrum, 39(1), 1-64.

Correia, M. H., Oliveira, J. F., \& Ferreira, J. S. (2004). Reel and sheet cutting at a paper mill. Computers E Operations Research, 31(8), 1223-1243.

Cui, Y., Zhong, C., \& Yao, Y. (2015). Pattern-set generation algorithm for the one-dimensional cutting stock problem with setup cost. European Journal of Operational Research, 243(2), 540-546.

Degraeve, Z., \& Jans, R. (2007). A new Dantzig-Wolfe reformulation and branch-and-price algorithm for the capacitated lot-sizing problem with setup times. Operations Research, 55(5), 909-920.

Degraeve, Z., \& Peeters, M. (2003). Optimal integer solutions to industrial cutting-stock problems: Part 2, benchmark results. INFORMS Journal on Computing, 15(1), $58-81$.

Diegel, A., Montocchio, E., Walters, E., van Schalkwyk, S., \& Naidoo, S. (1996). Setup minimising conditions in the trim loss problem. European Journal of Operational Research, 95(3), 631-640.

Drexl, A., \& Kimms, A. (1997). Lot sizing and scheduling - survey and extensions. European Journal of Operational Research, 99(2), 221-235.

Dyckhoff, H. (1981). A new linear programming approach to the cutting stock problem. Operations Research, 29(6), 1092-1104.

Dyckhoff, H. (1990). Cutting and packing a typology of cutting and packing problems. European Journal of Operational Research, 44(2), 145-159.

Dyckhoff, H., Kruse, H.-J., Abel, D., \& Gal, T. (1985). Trim loss and related problems. Omega, 13(1), 59-72.

Dyckhoff, H., Scheithauer, G., \& Terno, J. (1997). Cutting and packing: An annotated bibliography. Annotated Bibliographies in Combinatorial Optimization, 393412.

Eppen, G. D., \& Martin, R. K. (1987). Solving multi-item capacitated lot-sizing problems using variable redefinition. Operations Research, 35(6), 832-848.

Farley, A. A. (1988). Mathematical programming models for cutting-stock problems in the clothing industry. The Journal of the Operational Research Society, 39(1), $41-53$.

Fiorotto, D. J., \& de Araujo, S. A. (2014). Reformulation and a lagrangian heuristic for lot sizing problem on parallel machines. Annals of Operations Research, 217(1), 213-231.

Fiorotto, D. J., de Araujo, S. A., \& Jans, R. (2015). Hybrid methods for lot sizing on parallel machines. Computers E' Operations Research, 63, 136-148.

Fiorotto, D. J., Jans, R., \& de Araujo, S. A. (2017). An analysis of formulations for the capacitated lot sizing problem with setup crossover. Computers \&' Industrial Engineering, 106, 338-350.

Foerster, H., \& Wäscher, G. (1998). Simulated annealing for order spread minimization in sequencing cutting patterns. European Journal of Operational Research, 110(2), 272-281.

Foerster, H., \& Wäscher, G. (2000). Pattern reduction in one-dimensional cutting stock problems. International Journal of Production Research, 38(7), 16571676.

Furini, F., \& Malaguti, E. (2013). Models for the two-dimensional two-stage cutting stock problem with multiple stock size. Computers \& Operations Research, 40(8), 1953-1962.

Garraffa, M., Salassa, F., Vancroonenburg, W., Vanden Berghe, G., \& Wauters, T. (2016). The one-dimensional cutting stock problem with sequence-dependent cut losses. International Transactions in Operational Research, $23,5-24$. 
Ghidini, C. T. L. S., Alem, D., \& Arenales, M. N. (2007). Solving a combined cutting stock and lot-sizing problem in small furniture industries. In Proceedings of the 6 th international conference on operational research for development (VI-ICORD).

Giannelos, N. F., \& Georgiadis, M. C. (2001). Scheduling of cutting-stock processes on multiple parallel machines. Chemical Engineering Research and Design, 79(7), 747-753.

Gilmore, P. C., \& Gomory, R. E. (1961). A linear programming approach to the cutting-stock problem. Operations Research, 9(6), 849-859.

Gilmore, P. C., \& Gomory, R. E. (1963). A linear programming approach to the cutting stock problem - part II. Operations Research, 11(6), 863-888.

Gilmore, P. C., \& Gomory, R. E. (1965). Multistage cutting stock problems of two and more dimensions. Operations Research, 13(1), 94-120.

Glock, C. H., Grosse, E. H., \& Ries, J. M. (2014). The lot sizing problem: A tertiary study. International Journal of Production Economics, 155, 39-51.

Golfeto, R. R., Moretti, A. C., \& de Salles Neto, L. L. (2009). A genetic symbiotic algorithm applied to the cutting stock problem with multiple objectives. Advanced Modeling and Optimization, 11(4), 473-501.

Gomes, A. M., Gonçalves, J. F., Alvarez-Valdés, R., \& de Carvalho, J. M. V. (2016). Preface to the special issue on cutting and packing. International Transactions in Operational Research, 23, 3-4.

Gopalakrishnan, M., Ding, K., Bourjolly, J.-M., \& Mohan, S. (2001). A tabu-search heuristic for the capacitated lot-sizing problem with set-up carryover. Management Science, 47(6), 851-863.

Gramani, M. C. N., \& França, P. M. (2006). The combined cutting stock and lot-sizing problem in industrial processes. European Journal of Operational Research, 174(1), 509-521.

Gramani, M. C. N., França, P. M., \& Arenales, M. N. (2009). A lagrangian relaxation approach to a coupled lot-sizing and cutting stock problem. International Journal of Production Economics, 119(2), 219-227.

Gramani, M. C. N., França, P. M., \& Arenales, M. N. (2011). A linear optimization approach to the combined production planning model. Journal of the Franklin Institute, 348(7), 1523-1536.

Gruson, M., Cordeau, J.-F., \& Jans, R. (2017). The impact of service level constraints in deterministic lot sizing with backlogging. Omega, in press, 1-13.

Guimarães, L., Klabjan, D., \& Almada-Lobo, B. (2014). Modeling lotsizing and scheduling problems with sequence dependent setups. European Journal of Operational Research, 239(3), 644-662.

Haessler, R. W. (1975). Controlling cutting pattern changes in one-dimensional trim problems. Operations Research, 23(3), 483-493.

Hendry, L. C., Fok, K. K., \& Shek, K. W. (1996). A cutting stock and scheduling problem in the copper industry. The Journal of the Operational Research Society, 47(1), 38-47.

Henn, S., \& Wäscher, G. (2013). Extensions of cutting problems: Setups. Pesquisa Operacional, 33, 133-162.

Hifi, M. (2002). Special issue: Cutting and packing problems. Studia Informatica Universalis, 2(1), 1-161.

Hinxman, A. I. (1980). The trim-loss and assortment problems: A survey. European Journal of Operational Research, 5(1), 8-18.

Jans, R. (2009). Solving lot-sizing problems on parallel identical machines using symmetry-breaking constraints. INFORMS Journal on Computing, 21(1), 123-136.

Jans, R., \& Degraeve, Z. (2004). Improved lower bounds for the capacitated lot sizing problem with setup times. Operations Research Letters, 32(2), 185-195.

Jans, R., \& Degraeve, Z. (2007). Meta-heuristics for dynamic lot sizing: A review and comparison of solution approaches. European Journal of Operational Research, 177(3), 1855-1875.

Jans, R., \& Degraeve, Z. (2008). Modeling industrial lot sizing problems: A review. International Journal of Production Research, 46(6), 1619-1643.

Kantorovich, L. V. (1960). Mathematical methods of organizing and planning production. Management Science, 6(4), 366-422.

Karimi, B., Ghomi, S. M. T. F., \& Wilson, J. M. (2003). The capacitated lot sizing problem: a review of models and algorithms. Omega, 31(5), 365-378.

Krarup, J., \& Bilde, O. (1977). Plant location, set covering and economic lot size: An 0 (mn)- algorithm for structured problems. In L. Collatz, G. Meinardus, \& W. Wetterling (Eds.), Numerische methoden bei optimierungsaufgaben band 3. In International Series of Numerical Mathematics: Vol. 36 (pp. 155-180). Birkhäuser Basel.

Krichagina, E. V., Rubio, R., Taksar, M. I., \& Wein, L. M. (1998). A dynamic stochastic stock-cutting problem. Operations Research, 46(5), 690-701.

Leão, A. P. S., \& Toledo, F. M. B. (2016). Decomposition methods for the lotsizing and cutting stock problem in paper industries. Technical Report. ICMC-USP.

Li, S. (1996). Multi-job cutting stock problem with due dates and release dates. Journal of the Operational Research Society, 47, 490-510.

Malik, M. M., Qiu, M., \& Taplin, J. (2009). An integrated approach to the lot sizing and cutting stock problems. In Proceedings of the international conference on industrial engineering and engineering management (IEEE) (pp. 1111-1115).

Manne, A. S. (1958). Programming of economic lot sizes. Management Science, 4(2), 115-135.

Martello, S., \& Toth, P. (1990). Knapsack problems: Algorithms and computer implementations. New York, NY, USA: John Wiley \& Sons, Inc.

Melega, G. M., de Araujo, S. A., \& Jans, R. (2016). Comparison of MIP models for the integrated lot-sizing and one-dimensional cutting stock problem. Pesquisa Operacional, 36, 167-196.

Menon, S., \& Schrage, L. (2002). Order allocation for stock cutting in the paper industry. Operations Research, 50(2), 324-332.
Morabito, R., Arenales, M. N., \& Yanasse, H. H. (2009). Special issue on cutting, packing and related problems. International Transactions in Operational Research, 16(6), 659.

Nonås, S. L., \& Thorstenson, A. (2000). A combined cutting-stock and lot-sizing problem. European Journal of Operational Research, 120(2), 327-342.

Nonås, S. L., \& Thorstenson, A. (2008). Solving a combined cutting-stock and lotsizing problem with a column generating procedure. Computers \& Operations Research, 35(10), 3371-3392.

Oliveira, J. F., \& Wäscher, G. (2007). Cutting and packing. European Journal of Operational Research, 183(3), 1106-1108.

Ouhimmou, M., D’Amours, S., Beauregard, R., Ait-Kadi, D., \& Singh Chauhan, S. (2008). Furniture supply chain tactical planning optimization using a time decomposition approach. European Journal of Operational Research, 189(3), 952-970.

Pochet, Y., \& Wolsey, L. A. (1988). Lot-size models with backlogging: Strong reformulations and cutting planes. Mathematical Programming, 40(1-3), $317-$ 335.

Pochet, Y., \& Wolsey, L. A. (2006). Production planning by mixed integer programming. Springer Science \& Business Media.

Poldi, K. C., \& de Araujo, S. A. (2016). Mathematical models and a heuristic method for the multiperiod one-dimensional cutting stock problem. Annals of Operations Research, 238(1), 497-520.

Poldi, K. C., \& Arenales, M. N. (2009). Heuristics for the one-dimensional cutting stock problem with limited multiple stock lengths. Computers $\mathcal{E}$ Operations Research, 36(6), 2074-2081.

Poltroniere, S. C., de Araujo, S. A., \& Poldi, K. C. (2016). Optimization of an integrated lot-sizing and cutting stock problem in the paper industry. Tendências em Matemática Aplicada e Computacional (TEMA), 17(3), 305-320.

Poltroniere, S. C., Poldi, K. C., Toledo, F. M. B., \& Arenales, M. N. (2008). A coupling cutting stock-lot sizing problem in the paper industry. Annals of Operations Research, 157(1), 91-104.

Prata, B. D. A., Pitombeira-Neto, A. R., \& de Moraes Sales, C. J. (2015). An integer linear programming model for the multiperiod production planning of precast concrete beams. Journal of Construction Engineering and Management, 141(10), 04015029.

Reinders, M. P. (1992). Cutting stock optimization and integral production planning for centralized wood processing. Mathematical and Computer Modelling, 16(1), 37-55.

Reinertsen, H., \& Vossen, T. W. (2010). The one-dimensional cutting stock problem with due dates. European Journal of Operational Research, 201(3), 701-711.

Respício, A., \& Captivo, M. E. (2002). Integrating the cutting stock problem in capacity planning. Department of Informatics and Centre of Operational Research, University of Lisbon/Portugal.

Rinaldi, F., \& Franz, A. (2007). A two-dimensional strip cutting problem with sequencing constraint. European Journal of Operational Research, 183(3), 13711384.

Robinson, P., Narayanan, A., \& Sahin, F. (2009). Coordinated deterministic dynamic demand lot-sizing problem: A review of models and algorithms. Omega, 37(1), 3-15.

Sahling, F., Buschkühl, L., Tempelmeier, H., \& Helber, S. (2009). Solving a multi-level capacitated lot sizing problem with multi-period setup carry-over via a fix-and-optimize heuristic. Computers \& Operations Research, 36(9), 2546-2553.

Santos, S. G., de Araujo, S. A., \& Rangel, M. S. N. (2011). Integrated cutting machine programming and lot sizing in furniture industry. Pesquisa Operacional para 0 Desenvolvimento, 3(1), 1-17.

Silva, E., Alvelos, F., \& Valério de Carvalho, J. M. (2014). Integrating two-dimensional cutting stock and lot-sizing problems. Journal of the Operational Research Society, 65(1), 108-123.

Silva, E., Viães, C., Oliveira, J. F., \& Carravilla, M. A. (2015). Integrated cutting and production planning: A case study in a home textile manufacturing company. In A. P. F. D. B. Póvoa, \& J. L. de Miranda (Eds.), Operations research and big data. In Studies in Big Data: Vol. 15 (pp. 213-220). Springer International Publishing.

Stadtler, H. (1990). A one-dimensional cutting stock problem in the aluminium industry and its solution. European Journal of Operational Research, 44(2), 209223.

Suliman, S. M. A. (2012). An algorithm for solving lot sizing and cutting stock problem within aluminum fabrication industry. In Proceedings of the international conference on industrial engineering and operations management.

Süral, H., Denizel, M., \& Wassenhove, L. N. V. (2009). Lagrangean relaxation based heuristics for lot sizing with setup times. European Journal of Operational Research, 194(1), 51-63.

Thomas, D. J., \& Griffin, P. M. (1996). Coordinated supply chain management. European Journal of Operational Research, 94(1), 1-15.

Toledo, F. M. B., \& Armentano, V. A. (2006). A lagrangian-based heuristic for the capacitated lot-sizing problem in parallel machines. European Journal of Operational Research, 175(2), 1070-1083.

Toscano, A., Rangel, S., \& Yanasse, H. H. (2017). A heuristic approach to minimize the number of saw cycles in small-scale furniture factories. Annals of Operations Research, 258(2), 719-746.

Trigeiro, W. W., Thomas, L. J., \& McClain, J. O. (1989). Capacitated lot sizing with setup times. Management Science, 35(3), 353-366.

Trkman, P., \& Gradisar, M. (2007). One-dimensional cutting stock optimization in consecutive time periods. European Journal of Operational Research, 179(2), 291-301. 
Umetani, S., Yagiura, M., \& Ibaraki, T. (2003). One-dimensional cutting stock problem to minimize the number of different patterns. European Journal of Operational Research, 146(2), 388-402.

Umetani, S., Yagiura, M., \& Ibaraki, T. (2006). One-dimensional cutting stock problem with a given number of setups: A hybrid approach of metaheuristics and linear programming. Journal of Mathematical Modelling and Algorithms, 5(1), 43-64.

Valério de Carvalho, J. M. (1999). Exact solution of bin-packing problems using column generation and branch-and-bound. Annals of Operations Research, 86(0), 629-659.

Valério de Carvalho, J. M. (2002). Lp models for bin packing and cutting stock problems. European Journal of Operational Research, 141(2), 253-273.

Vance, P. H., Barnhart, C., Johnson, E. L., \& Nemhauser, G. L. (1994). Solving binary cutting stock problems by column generation and branch-and-bound. Computational Optimization and Applications, 3(2), 111-130.

Vanderbeck, F. (2000). Exact algorithm for minimising the number of setups in the one-dimensional cutting stock problem. Operations Research, 48(6), 915926.

Vanzela, M., Melega, G. M., Rangel, S., \& de Araujo, S. A. (2017). The integrated lot sizing and cutting stock problem with saw cycle constraints applied to furniture production. Computers \& Operations Research, 79, 148-160.

Viegas, J. L., Vieira, S. M., Henriques, E. M., \& Sousa, J. M. (2016). Heuristics for three-dimensional steel cutting with usable leftovers considering large time periods. European Journal of Industrial Engineering, 10(4), 431-454.

Wagner, H. M., \& Whitin, T. M. (1958). Dynamic version of the economic lot size model. Management Science, 5(1), 89-96.
Wang, P. Y., \& Wäscher, G. (2002). Cutting and packing. European Journal of Operational Research, 141(2), 239-240.

Wäscher, G. (1990). An lp-based approach to cutting stock problems with multiple objectives. European Journal of Operational Research, 44(2), 175-184.

Wäscher, G., \& Gau, T. (1996). Heuristics for the integer one-dimensional cutting stock problem: A computational study. Operations-Research-Spektrum, 18(3), 131-144.

Wäscher, G., Haußner, H., \& Schumann, H. (2007). An improved typology of cutting and packing problems. European Journal of Operational Research, 183(3), 1109-1130.

Wu, T., Akartunali, K., Jans, R., \& Liang, Z. (2017). Progressive selection method for the coupled lot-sizing and cutting-stock problem. INFORMS Journal on Computing, 29(3), 523-543.

Wuttke, D. A., \& Heese, H. S. (2018). Two-dimensional cutting stock problem with sequence dependent setup times. European Journal of Operational Research, 265(1), 303-315.

Yanasse, H. H., \& Katsurayama, D. M. (2005). Checkerboard pattern: proposals for its generation. International Transactions in Operational Research, 12(1), 21-45.

Yanasse, H. H., \& Lamosa, M. J. P. (2007). An integrated cutting stock and sequencing problem. European Journal of Operational Research, 183(3), 1353-1370.

Yanasse, H. H., \& Limeira, M. S. (2006). A hybrid heuristic to reduce the number of different patterns in cutting stock problems. Computers \& Operations Research, 33(9), 2744-2756. 